FUEL CONSUMPTION AND GASOLINE PRICES:

THE ROLE OF ASSORTATIVE MATCHING BETWEEN HOUSEHOLDS AND AUTOMOBILES

\author{
H. Spencer Banzhaf \\ Taha Kasim \\ Working Paper 22983 \\ http://www.nber.org/papers/w22983 \\ NATIONAL BUREAU OF ECONOMIC RESEARCH \\ 1050 Massachusetts Avenue \\ Cambridge, MA 02138 \\ December 2016, Revised August 2017
}

We thank Kenneth Gillingham, Shanjun Li, Joshua Linn, Kyle Mangum, Michael Price, Roger von Haefen, and participants in the ASU environmental economics conference, a Cornel University (Dyson School) seminar, Camp Resources, and a GSU workshop for helpful comments. We also thank Mark Jacobsen for sharing and explaining the data and code used to create the instrument based on Bento et al. (2009). We thank the staff at the U.S. Department of Transportation (DOT) for assistance in obtaining the confidential NHTS data files. The views expressed herein are those of the authors and do not necessarily reflect the views of the National Bureau of Economic Research.

NBER working papers are circulated for discussion and comment purposes. They have not been peer-reviewed or been subject to the review by the NBER Board of Directors that accompanies official NBER publications.

(C) 2016 by H. Spencer Banzhaf and Taha Kasim. All rights reserved. Short sections of text, not to exceed two paragraphs, may be quoted without explicit permission provided that full credit, including $(\odot$ notice, is given to the source. 
Fuel Consumption and Gasoline Prices: The Role of Assortative Matching between Households and Automobiles

H. Spencer Banzhaf and Taha Kasim

NBER Working Paper No. 22983

December 2016, Revised August 2017

JEL No. Q4,Q5

\begin{abstract}
Analyses of policies to reduce gasoline consumption have focused on two effects, a compositional effect on the fuel economy of the automotive fleet and a utilization effect on how much people drive. However, the literature has missed a third effect: a matching effect, in which the policy changes how high-utilization households are matched to fuel-efficient vehicles in equilibrium. We show that higher gas prices should lead to stronger assortative matching. Empirical estimates using US micro-level data are consistent with this hypothesis. We find a $\$ 1$ gas tax would reduce US gas consumption by $1.5 \%$ through the matching effect alone.
\end{abstract}

\author{
H. Spencer Banzhaf \\ Department of Economics \\ Andrew Young School of Policy Studies \\ Georgia State University \\ P.O. Box 3992 \\ Atlanta, GA 30302 \\ and NBER \\ hsbanzhaf@gsu.edu \\ Taha Kasim \\ Dept. of Economics, Furman Univ. \\ 3300 Poinsett Hwy. \\ Greenville, SC 29613 \\ mohammed.taha@furman.edu
}




\title{
Fuel Consumption and Gasoline Prices: The Role of Assortative Matching between Households and Automobiles*
}

\author{
H. Spencer Banzhaf ${ }^{\dagger}$ \\ Taha Kasim*
}

July 2017

\begin{abstract}
Analyses of policies to reduce gasoline consumption have focused on two effects, a compositional effect on the fuel economy of the automotive fleet and a utilization effect on how much people drive. However, the literature has missed a third effect: a matching effect, in which the policy changes how high-utilization households are matched to fuel-efficient vehicles in equilibrium. We show that higher gas prices should lead to stronger assortative matching. Empirical estimates using US micro-level data are consistent with this hypothesis. We find a 1 gas tax would reduce US gas consumption by $1.5 \%$ through the matching effect alone.
\end{abstract}

\section{Introduction}

Both to reduce dependency on petroleum imports and to reduce air pollution, many countries seek to reduce gasoline consumption from passenger vehicles. In the United States, passenger vehicles account for $16 \%$ of all greenhouse gas emissions (US EPA 2015 p. 2-28). Additionally, they are a major source of conventional pollutants such as carbon monoxide, ozone, and fine particulates. These pollutants can cause such health effects as headache, respiratory disease, heart disease and premature mortality. They may be particularly potent in such vulnerable populations as the elderly and young children. Indeed, studies have shown that in-utero and childhood exposure to these

\footnotetext{
${ }^{*}$ We thank Kenneth Gillingham, Shanjun Li, Joshua Linn, Kyle Mangum, Michael Price, Roger von Haefen, and seminar and workshop participants at the ASU environmental economics conference, Camp Resources, Cornel University, Georgia State University, and UC Santa Barbara for helpful comments. We also thank Mark Jacobsen for sharing and explaining the data and code used to create the instrument based on Bento et al. (2009). We thank the staff at the U.S. Department of Transportation (DOT) for assistance in obtaining the confidential NHTS data files.

${ }^{\dagger}$ Professor, Dept. of Economics, Georgia State Univ., hsbanzhaf@gsu.edu.

*Visiting Assistant Professor, Dept. of Economics, Furman Univ., mohammed.taha@furman.edu.
} 
gasses have the potential to affect various health outcomes in the short- and the long-run (Currie et al. 2014).

Policies to reduce gasoline consumption generally fall into two main categories: pricebased policies and performance-based policies. Price-based policies such as a gasoline tax work by making driving more expensive. Among OECD countries, the US has the lowest gasoline taxes save Mexico, at $\$ 0.53$ per gallon (average state plus federal tax) as of 2013 , compared to $\$ 4.73$ in the UK and \$4.54 in Germany (OECD 2014). Performance-based policies mandate minimum average fuel economy standards for the fleet. Examples include the US Corporate Average Fuel Economy (CAFE) standards and similar policies in Europe, Japan, and elsewhere.

Traditionally, the literature assessing the effectiveness of such policies has decomposed their effects into two channels: a compositional effect, relating to the average fuel efficiency of the fleet, and a utilization effect, relating to how much people drive (e.g. Bento et al. 2009; Goldberg 1998; Li, Timmins, and von Haefen 2009; Puller and Greening 1999). By increasing the cost of driving, gas taxes create an incentive to drive less as well as to obtain a more fuel efficient car. Thus, they operate through both channels. Performance standards like CAFE mandate more fuel efficient cars (on average), but do not create incentives to drive less - indeed, by putting people in more fuel efficient cars they reduce the cost of driving and increase utilization (the so-called "rebound effect"). Bento et al. (2009) and Gillingham (2012) measure both the compositional and the utilization effects using structural models in which household simultaneously choose an automobile and their level of driving in a consistent framework. They find that the utilization effect is bigger than the compositional effect.

In this paper, we show that this large literature has overlooked a third effect of such policies, a sorting or matching effect. In theory, even if the compositional and utilization effects are 
held to zero - that is, even if the fleet remains exactly the same and each individual drives exactly the same number of miles annually - an increase in gasoline prices could still reduce gasoline consumption if it leads to stronger assortative matching between high-utilization households and the fuel efficiency of the cars they drive. Intuitively, if a household does little driving, the fuel efficiency of its car has little impact on overall consumption (at the extreme, a car parked in the garage burns no gas regardless of its fuel efficiency), whereas if a household drives great distances the fuel efficiency of its car matters a good deal. Conversely, if a car is very fuel efficient, its utilization has little impact on overall consumption (at the extreme, the utilization of a bicycle would not matter), whereas if a car is fuel inefficient its utilization matters a good deal.

While the literature has long understood that, ceteris paribus, high-utilization households are more likely to choose low-energy alternatives (thus motivating the simultaneous modeling of a household's choice of a product's energy efficiency together with its utilization), to our knowledge the effect of a change in gas prices or other policies on how households are matched to products in equilibrium has been widely neglected in the literature. ${ }^{1}$ Yet it is not trivial. To gauge the potential importance of the matching effect, if household demand for VMT and vehicle fuel efficiency were perfectly matched in 2009 , gasoline consumption would have been $15 \%$ lower, even with no change in the composition of the fleet and no change in individuals' utilization.

In addition to pointing out the importance of this effect, in this paper we show that, a priori, there are good reasons to believe that higher gasoline prices increase the degree of matching. The intuition is as follows. Increases in gasoline prices increase demand for fuel-efficient cars relative

\footnotetext{
${ }^{1}$ The importance of such simultaneity has been noted since at least Dubin and McFadden (1984). In the context of automobiles, Anderson, Kellogg, and Sallee (2013) speculate that in a cross section, fuel efficient vehicles should be assortatively matched to households who drive long distances. We are more agnostic about such relationships in any one cross section, but show that this relationship can be affected by prices and other policy parameters.
} 
to inefficient ones, because the monetary savings of owning an efficient vehicle increase. But there is exogenous heterogeneity among households in their utilization. When gasoline prices rise, the savings of owning an efficient vehicle increase more for higher-utilization households than for low-utilization households. Consequently, high-utilization households are now comparatively more likely to outbid low-utilization households for fuel-efficient cars (ceteris paribus). Thus, when gas prices increase, high-utilization households tend to be allocated more fuel-efficient cars than before, while low-utilization households are allocated less efficient cars. Accordingly, in equilibrium, after an increase in the gasoline prices, there should be a stronger assortative matching from households, based on the amount of driving they are likely to do, to the fuel economy of the cars they own.

Finally, we test this hypothesis empirically. Using data from the US National Highway Transportation Survey, we adopt a difference-in-differences framework, comparing the way (exogenously) high-utilization households change the fuel economy of their car when gas prices increase relative to the way low-utilization households do. Given our difference-in-difference framework, we interpret our results as short-run responses. We find a statistically significant short-run matching effect from gas prices that is robust to a variety of identification strategies, including ordinary least squares (OLS) and different ways of instrumenting for utilization. Specifically, we find that when gasoline prices increase by $\$ 1$, a household responds on average by driving a vehicle that gives 0.01 to 0.05 more miles per gallon for every 1,000 miles it drives in the short run. Using variation only in gasoline taxes, we find an effect of 0.03 to 0.06 miles per gallon for every 1,000 miles. While these matching effects may seem small, in the aggregate they correspond to a savings of about $1.5 \%$ of fuel consumption, or 1.9 billion gallons, annually for a $\$ 1$ increase in taxes. These savings in turn correspond to 84 million tonnes of carbon dioxide $\left(\mathrm{CO}_{2}\right)$ emissions and 
environmental damages of about $\$ 3.3$ billion. These effects are likely to be bigger in the long run.

Insofar as it focuses on households' choices for fuel efficiency at the extensive margin and how such choices are affected by gasoline prices, our paper relates to the large literature on automobile demand and the compositional effect, including Allcot and Wozny (2014); Austin and Dinan (2005); Bento et al. (2009); Busse, Knittel, and Zettelmeyer (2013); Feng, Fullerton, and Gan (2013); Gillingham (2012); Goldberg (1998); Jacobsen (2013); Klier and Linn (2010); Li, Linn, and Muehlegger (2014); Li, Timmins, and von Haefen (2009); Puller and Greening (1999); and Sallee, West, and Fan (2016). Overall, this literature has found that an increase in gasoline prices increases the demand for more fuel efficient cars, which in equilibrium modestly nudges the composition of the automobile fleet toward fuel efficiency. In particular, new cars entering the fleet become more fuel efficient while older inefficient cars are scrapped more rapidly. Interestingly, Allcot and Wozny (2014); Busse, Knittel, and Zettelmeyer (2013); and Sallee, West, and Fan (2016) find that, in between, the shift in demand manifests in price rather than quantity effects, with the prices of fuel-efficient used cars rising relative to inefficient cars when gas prices rise. Our work can be viewed as exploring the heterogeneity in these demand effects at the extensive margin, showing that they are larger for (exogenously) higher-utilization households than lowerutilization households. In equilibrium, this gives rise to more assortative matching, which in turn becomes a third channel through which gas prices affect gasoline consumption.

The rest of the paper is structured as follows: Section II explains the matching effect using a theoretical model; Section III introduces the basic empirical approach and describes the data; Section IV presents the results and briefly discusses the implications; and Section V concludes. 


\section{Theoretical Framework}

\section{A. Conceptual Basics}

Consider an economy with a set $\mathcal{C}$ of cars indexed by $c$ and a set $\mathcal{J}$ of individuals indexed by $i$. These sets have the same measure, which we normalize to one, and in equilibrium there is a bijective mapping of cars to individuals. Individual i's fuel use is equal to its utilization, measured in vehicle miles travelled (VMT), times the inverse of the fuel efficiency of its car, or gallons per mile (GPM):

$$
F U E L_{i}=V M T_{i} \times G P M_{c(i)},
$$

where $c(i)$ represents the car assigned to individual $i$.

From this simple tautology, it would seem that changes in fuel use can be decomposed into two effects, a change in VMT (utilization) and a change in fuel economy (GPM). While this is true at the individual level, to extend it to the over-all economy is to commit the fallacy of composition. Overall fuel usage is the sum over all individuals of these products:

$$
\text { TOTAL FUEL }=\int_{\mathcal{J}} V M T_{i} \times G P M_{c(i)} f(i) d i,
$$

where $f()$ is the density. This sum of products can be rewritten as

$$
\text { TOTAL FUEL }=\overline{V M T} \times \overline{G P M}+\operatorname{COV}(V M T, G P M) .
$$

Thus, changes in total fuel consumption can be decomposed into three effects: the utilization effect measured in changes in average VMT, the compositional effect measured in changes in the average GPM of the fleet, and the matching effect which represents changes in the covariance between a households VMT and the GPM of the car assigned to it in equilibrium. Though seemingly obvious when written this way, to our knowledge the existence of this third effect—and in particular how it might be affected by policies — has been overlooked in the literature.

Our hypothesis is that when gasoline prices increase, high-GPM cars (i.e. fuel-inefficient 
ones) will tend more strongly to be assigned to low-VMT households. Thus, the covariance between VMT and GPM will decrease and total fuel usage will fall, even holding constant average VMT and average GPM (indeed, even holding constant every individual's VMT and every vehicle in the fleet).

The argument for this hypothesis comprises two basic steps. First, when gasoline prices increase, the demand for high-GPM cars falls relative to the demand for low-GPM cars, andmore to our point - this shift is greater for high-VMT households. Second, in equilibrium, this shift in demands leads to a more systematic assignment of high-GPM cars to low-VMT households. Because it is a simpler point to make, we begin with the second point first.

\section{B. The Matching Effect}

A partial equilibrium model is sufficient to explain how this shift in relative demands leads to the matching effect. For simplicity, let there be two types of households that differ only in terms of what Gillingham (2012) calls their "utilization type," or their demand for VMT for reasons exogenous to the choice of car: thus, there are high-utilization households $(H)$ and low-utilization households $(L)$. Let there be two car types: fuel-inefficient $(I)$ and fuel-efficient $(E)$. In Figure 1, Panel A shows the demand for high-GPM cars relative to low-GPM cars. Heterogeneity in the relative demand for such cars is reflected by $D^{H}$ and $D^{L}$, which indicate the relative marginal willingness to pay (WTP) of each respective household type. This WTP could be positive or negative, depending on which car type is preferred. Additionally, we take no stand on whether the high-VMT types or the low-VMT types have a higher relative WTP for such cars: high-VMT types may want them more than low-VMT types for their comfort when driving, or want them less than low-VMT types because of their operating cost. As an illustration, Figure 1 shows an example of a baseline scenario where $D_{0}^{H}=D_{0}^{L}$. The market demand is $D_{0}$ and the relative price is $P_{0}$. The 
supply elasticity plays no role in the argument; in this example, the market supply curve is perfectly inelastic, as might be consistent with the market for used cars too young to be scrapped.

Panel A depicts a situation where gasoline prices increase, so the relative WTP for highGPM vehicles falls. The new market demand is $D_{1}$ and the price falls to $P_{1}$ in the vehicle market. This is consistent with the findings of Allcott and Wozny (2014); Busse, Knittel, and Zettelmeyer (2013); and Sallee, West, and Fan (2016). Our insights hinge on the fact that the relative WTP for a high-GPM automobile will particularly decrease for the high-utilization types, as higher gasoline prices translate into greater costs for them. This is shown in this figure where $D_{1}^{H}$ is now lower than $D_{1}^{L}$. As a consequence, in equilibrium, the low-VMT types now have a greater share of the high-GPM vehicles than before $\left(\frac{A}{A+B}\right.$ versus $\left.\frac{1}{2}\right)$. By the same logic, as shown in Panel B, the highVMT types now have a greater proportion of low-GPM vehicles relative to the baseline case.

Consequently, the correlation between VMT and fuel inefficiency is now lower, so that the covariance in Equation (3) is now lower with higher gas prices. (Equivalent, the correlation between VMT and fuel economy is higher.) In the empirical portion of this paper, we test this hypothesis directly by looking at the matching of car types to utilization types under variation in gasoline prices.

Before getting to that empirical work, however, we must complete the argument by showing that the demand for fuel inefficient cars does shift back more among high utilization types than low utilization types when gas prices rise.

\section{Relative Shifts in Demand}

We begin by generalizing our two-car, two-household model to continuums of types. In particular, let $\mathcal{C}$ be a simply ordered set of cars such that for any two elements $c, c^{\prime} \in \mathcal{C}, c^{\prime}>c \leftrightarrow$ $G P M_{c^{\prime}}>G P M_{c}$. In differentiating cars only by their GPM, we do not imply that mileage is the only 
relevant factor. To the contrary, we allow for the possibility that as GPM increases, the car becomes more desirable in other ways such as increased horsepower and/or comfort, or perhaps less desirable, if it is cheaper.

Additionally, we assume that individuals can be ranked according to their utilization type. In particular, let $\pi(i, c, V M T)$ be individual i's inverse demand curve, or marginal WTP, for VMT conditional on being in car $c$. We make the following assumption about the ordering of $\mathcal{J}$ :

Assumption A1. For any two elements $i, i^{\prime} \in \mathcal{J}$, if $i^{\prime}>i$ then $\pi\left(i^{\prime}, c, V M T\right)>\pi(i, c, V M T)$ everywhere.

That is, as we go through the index $i$, the demand curves for VMT, conditional on any car $c$, shift up. Note Assumption A1 does not necessarily imply that $V M T_{i^{\prime}}>V M T_{i}$. For one thing, $i$ and $i^{\prime}$ may face different gas prices. Moreover, they may choose different cars, which also affects their VMT choice. Assumption A1 only implies that, if they were in the same arbitrary car and faced the same prices, $i^{\prime}$ would choose higher VMT than $i$.

With these preliminaries, consider now the WTP of some household $i$ for an arbitrary car $c$, relative to having no car at all, which is a function of gasoline prices $p^{G}$ :

$$
\begin{aligned}
W T P\left(c, i, p^{G}\right) & =f(c, i)+\int_{0}^{V M T^{*}\left(i, c, p^{G}\right)} \pi(i, c, V M T) d V M T \\
& -V M T^{*}\left(i, c, p^{G}\right) G P M(c) p^{G} .
\end{aligned}
$$

The individual's WTP for car $c$ comprises three terms. The first term $f()$ represents a value unrelated to actually driving the car. It represents an option value of having it in the garage, a collector's value, or some similar utility value. The remaining two terms represent the consumer surplus from driving the car. Integrating under $\pi($ ) up to the optimal level of driving given gasoline prices, $V M T^{*}\left(i, c, p^{G}\right)$, gives the total (gross) value of driving car $c$. From this, we subtract the cost of driving car $c$ when gasoline prices are $p^{G}$, which is $V M T^{*}\left(i, c, p^{G}\right) G P M(c) p^{G}$. In equilibrium, 
an individual buys the car with the highest consumer surplus, after subtracting out the price of purchasing the car.

Our model depends on the triple difference among car types, utilization types, and gasoline prices - that is, on how WTP differs by car type, how that difference differs by utilization type, and how that difference-in-difference differs with gasoline prices. For simplicity, assume that all the functions in Equation (4) are twice differentiable in all their arguments. ${ }^{2}$ In Appendix A, we derive the following relationship on the third partial cross derivative of WTP:

$$
\begin{gathered}
-\frac{\partial V M T^{*}\left(i, c, p^{G}\right)}{\partial i} \frac{d G P M(c)}{d c} \\
\frac{\partial^{3} W T P\left(i, c, p^{G}\right)}{\partial i \partial c \partial p^{G}}=+\frac{\partial^{2} V M T^{*}\left(i, c, p^{G}\right)}{\partial c \partial p^{G}} \frac{\partial \pi\left(i, c, V M T^{*}\right)}{\partial i} \\
+\frac{\partial V M T^{*}\left(i, c, p^{G}\right)}{\partial p^{G}} \frac{\partial^{2} \pi\left(i, c, V M T^{*}\right)}{\partial i \partial c}-\frac{\partial^{2} V M T^{*}\left(i, c, p^{G}\right)}{\partial i \partial c} G P M \\
+\frac{\partial^{2} V M T^{*}\left(i, c, p^{G}\right)}{\partial i \partial p^{G}}\left[\frac{\partial \pi\left(i, c, V M T^{*}\right)}{\partial c}-\frac{d G P M(c)}{d c} p^{G}\right] .
\end{gathered}
$$

Note here that, in taking the partial derivative with respect to $c$, we are taking the car type $c$ as exogenous, so there are no effects of $p^{G}$ or utilization type on the optimal choice of $c$.

Conditional on this car, the individual does optimally choose VMT. At equilibrium, the individual sets marginal WTP for an additional mile equal to the cost, so $\pi\left(i, c, V M T^{*}\right)=$ $G P M(c) p^{G}$. As we take the derivatives of the two sides of this expression with respect to $c$, we get two effects. If better performance accompanies the increase in $c$, then the marginal WTP for an addition mile increases, $\partial \pi / \partial c>0$, through a utility or comfort effect, as driving becomes more comfortable and/or more fun (West et al. 2016). But at the same time, the actual price paid for an additional mile increases through the $G P M$ effect, that is $G P M^{\prime}(c) p^{G}>0$. Thus, what we call the overall car effect on $V M T$, i.e. $\partial V M T^{*} / \partial c$, cannot be signed a priori. However, it is the opposite

\footnotetext{
${ }^{2}$ This assumption is not necessary but simplifies the presentation.
} 
sign as the "rebound effect," which is generally estimated to be positive (Gillingham et al. 2013, Linn 2016, Small and van Dender 2007, West et al. 2016). A crucial question when evaluating Equation (5) turns out to be the difference in the car effect on VMT between different values of $i$. Consider the following Assumption:

Assumption A2. $\partial^{2} \pi / \partial i \partial c \geq 0$ everywhere.

Because the effect on operating costs is the same at a given car for all household types, $\mathrm{A} 2$ implies that the car effect on VMT is non-decreasing in $i, \partial^{2} V M T / \partial i \partial c \geq 0$. Thus, as $i$ exogenously moves from $c$ to $c^{\prime}$ it might decrease its VMT, whereas a higher utilization type $i$ ' will decrease VMT less or perhaps increase it. Assumption A2 is stronger than A1 but is consistent with the idea that demand for driving is increasing in $i$. For example, Assumption A2 is consistent with inverse demand curves for VMT that are proportional in $c$ and $i$.

Assumption A2 is sufficient for the following proposition:

Proposition: $\frac{\partial^{3} W T P\left(i, c, p^{G}\right)}{\partial i \partial c \partial p^{G}}<0$ so long as either (i) the car effect on VMT is sufficiently small or (ii) it is the same sign as $\partial^{2} V M T^{*} / \partial i \partial p^{G}$.

A proof of the proposition can proceed by inspecting each line on the right-hand side of Equation (5). The first line is negative, since by definition of our ordered sets, $\frac{\partial V M T^{*}}{\partial i}>0$ and $\frac{d G P M}{d c}>0$. This line, the lowest-order term in Equation (5), represents the basic intuition for why the triple difference is negative. As gas prices increase, operating high-GPM cars becomes more expensive, but this is especially true for high-utilization types.

Completing the proposition requires considering the higher-order terms in Equation (5). The second line also is negative. $\partial \pi / \partial i$ is positive by Assumption A1. $\partial^{2} V M T / \partial c \partial p^{G}$ is negative because, by the law of demand, VMT is decreasing in the effective price of driving, which is 
$G P M(c) p^{G}$, and the effect of a given change in gasoline prices on the effective price of driving is greater for higher-GPM vehicles.

The third line is non-positive by Assumption A2. In the first term, Assumption A2 states that $\partial^{2} \pi / \partial i \partial c$ is non-negative, and it is multiplied by $\partial V M T^{*} / \partial p^{G}$ which is negative by the law of demand. In the second term, $\partial^{2} V M T^{*} / \partial i \partial c$ also is non-negative by Assumption $\mathrm{A} 2$ and of course GPM is positive. This third line is the only place we use Assumption A2. Notice that it is actually a sufficient—not necessary—condition: It would suffice for $\partial^{2} V M T^{*} / \partial c \partial i$ to be "not too negative" rather than non-negative.

This then leaves the last line of Equation (5) as the only term that cannot be signed definitively a priori. The Proposition requires either that this line not be large and positive. The term in square brackets is the same sign as the car effect on VMT, which is the negative of the rebound effect. $\partial \pi / \partial c$ represents the comfort effect (positive if $c$ comes with performance) while $d G P M(c) / d C$ represents the GPM effect. The literature on the rebound effect suggests this entire term is probably small and certainly negative (Gillingham et al. 2013, Linn 2016, Small and van Dender 2007, West et al. 2016). If so, then the proposition requires in turn that the first term in the product, $\partial^{2} V M T^{*} / \partial i \partial p^{G}$, not be large and negative. Unfortunately, the term cannot be signed definitively. $\partial V M T^{*} / \partial i$ is positive by Assumption A1, but whether VMT becomes more or less responsive to changes in gasoline prices with utilization type is another question. However, if VMT becomes less price elastic with increasing utilization types, as seems plausible, then this term is positive, which would be consistent with the proposition. For it to be negative and large enough to undermine the proposition, it would have to be the case that the-low utilization types reduce their VMT more than the high types when gas prices increase, which, coupled with the general desire to reduce VMT when switching to a larger car, creates such a larger second-order effect on 
the lost consumer surplus from driving, that low-utilization types will not begin to outbid the highutilization types for the larger car. This seems unlikely.

Under Assumption A2 (and the caveats in the previous paragraph), the Proposition states that as gasoline prices increase, the demand for high-GPM cars falls relative to the demand for low-GPM cars more so for high-utilization types than for low-utilization types. This is the key result of this sub-section. Given the equilibrium results in the previous sub-section, the implication is that as gasoline prices increase, the correlation between utilization and GPM decreases (or increases between utilization and MPG).

\section{Empirical Strategy and Data}

\section{A. Empirical Strategy}

Our basic strategy for testing our hypothesis is to run the following difference-in-differences regression. The model compares the fuel economy of cars matched to high-utilization households to those matched to low-utilization households among year/quarter-MSA cells with comparatively high and low gasoline prices. Our preferred specification is:

$$
\begin{gathered}
M P G_{i c m t}=\alpha+\beta \text { Price }_{m t}^{g a s}+\gamma V M T_{i c m t}+\theta\left[\text { Price }_{m t}^{\text {gas }} \times V M T_{i c m t}\right] \\
+\mathbf{x}_{i m t}{ }^{\prime} \boldsymbol{\delta}+\eta_{m}+\lambda_{t}+\varepsilon_{i c m t}
\end{gathered}
$$

where $M P G_{i c m t}=1 / G P M_{i c m t}$ is miles per gallon of vehicle $c$ owned by household $i$ in metro area

$m$ in quarter $t$, Price mt $_{\text {as }}$ is the per gallon price of gasoline in metro $m$ in year $t, V M T_{i c m t}$ is VMT of vehicle $c$ owned by household $i, \mathbf{x}_{i m t}$ are demographic variables of household $i, \eta_{m}$ are MSA dummies, $\lambda_{t}$ is a year dummy and $\varepsilon_{i c m t}$ is an idiosyncratic error term. The matching effect of higher gasoline prices is represented by $\theta$ and our hypothesis is that $\theta>0$. In Equation (6), $\lambda_{t}$ controls for time-varying unobservables and $\eta_{m}$ controls for time-invariant city-specific unobservables. 
Four points about our empirical strategy deserve further comment. First, because we include year and MSA dummies, and because (as discussed below) we use contemporaneous gas prices, we view our estimates as short run effects. Given the transaction costs involved in changing cars, we would expect the effects to be higher in the long run.

Second, we assume gasoline prices are exogenous. In doing so, it is important to emphasize that we are using micro-level data with city and year dummies. Thus, we assume deviations in tastes for MPG from the city's long-run average (insofar as they differ from national deviations) are uncorrelated with city-quarter gas prices. In an alternative specification, we use city-month dummies, thereby absorbing city-month averages in MPG demand, which might be correlated with changing city-level macroeconomic conditions and gas prices. This alternative specification reduces the error in Equation (6) to individual-level deviations from the city-month means. As another alternative, we also instrument for gasoline prices using gasoline taxes.

Third, in our basic approach using OLS, we also assume that VMT is exogenous to the fuel efficiency of the car. However, as discussed above, VMT and MPG likely are chosen simultaneously. If the MPG effect outweighs the comfort effect, households with more fuel efficient vehicles drive more, which is consistent with the rebound effect. With the exception of Linn (2016), recent evidence has suggested that this effect is fairly small (Gillingham et al. (2013), Small and van Dender (2007), West et al. 2016). If so, this endogeneity problem is probably small enough to ignore and OLS will be unbiased. Accordingly, we first use OLS to estimate Equation (6). However, in the following section we also consider a variety of instrumental variables (IV) strategies, including interactions of household characteristics with gasoline prices and nonlinearities inherent in the structural model of Bento et al. (2013). We generally find our results are robust to these approaches. 
Fourth, in the data (described below) VMT is observed on the car, not the individual. Thus, $V M T_{i c m t}$ is the VMT of the car, not an individual or household. In households with only one car, these would be observationally equivalent. In households with multiple cars, this raises the question of how cars are assigned to individuals. In our base model, we effectively treat the data as if multi-car households not only have an exogenous total VMT, but an exogenous split of VMT into baskets to be assigned to cars. For example, if a household has two cars with 10,000 and 5,000 VMT respectively, we treat the household as first exogenously splitting its total VMT into one basket of 10,000 miles and one of 5,000. However, we treat the assignment of cars to these VMT baskets as an endogenous choice. Thus, whether the 10,000 mile basket goes to one car and the 5,000 to the other or vice versa is treated in our approach as a choice which can change under differing economic conditions. This approach allows for some within-household matching insofar as a high-VMT individual in a household can be more likely to be assigned the high-MPG car in the household as gasoline prices increase. However, it is conservative in that it does not allow VMT to otherwise be shifted to the high-MPG car, as it forces the split to stay constant $(10,000$ and 5,000 in this example). As an alternative, we also consider each household, rather than each car, as a unit, using only one car per household or alternatively per-car VMT and average fuel economy of all cars in the household. This approach is even more conservative as it removes all within-household matching.

\section{B. Data}

Our data can be divided into three categories: (i) a confidential version of the 2001 and the 2009 National Household Travel Survey (NHTS), which surveys a random sample of US households about the cars they own and their VMT for each car; (ii) quarterly gasoline prices from 2001-2 and 2008-9 at the city level, purchased from the American Chamber of Commerce's ACCRA Cost of 
Living Index (COLI) database; and (iii) data on the fuel economy of automobiles by make and model, from the U.S. Department of Energy. These data were merged to produce a distinct dataset which provides information on driving habits, household characteristics, average gasoline prices paid and the fuel economy of vehicles owned by these households.

The 2009 NHTS was conducted between March 2008 and May 2009 and the 2001 NHTS was conducted from March 2001 through June 2002. The raw 2009 NHTS samples consisted of 338,184 observations (cars) for 172,105 households, from both urban and rural areas in the US; the 2001 NHTS sample consisted of 143,457 observations for 69,800 households. Unfortunately, in 2001, many of the observations are missing information needed to compute MPG or could not be matched to gasoline prices. After dropping these missing values and otherwise cleaning the data, we are left with 263,270 observations for 137,868 households in the 2009 sample and 63,102 observations for 35,464 households in the 2001 sample. $^{3}$ Both data sets contain information on household driving patterns, including VMT and the type of car(s) owned by the household (make, model, vintage). ${ }^{4}$ Furthermore, the survey includes demographic data about the household (income, number of household members, age distribution, race, work status). The confidential NHTS

\footnotetext{
${ }^{3}$ In 2001, 27,956 observations (23.0\% of observations with VMT data) are missing information on the model or other information necessary for computing MPG; in 2009, 3,909 observations (1.3\%) are missing such data. Additionally, in 2001 13,857 observations (17.8\%) could not be assigned gasoline prices. In both survey waves, annual miles ranged from 0 to 200,000 miles. However, following Bento et al. (2009), mileage below 100 and above 60,000 indicate possible coding errors and so were dropped. This resulted in 3,487 (2.9\%) and 7,894 (2.6\%) observations dropped from the 2001 and 2009 NHTS data, respectively. Additionally, vehicles that were more than 24 years old were not identified in the 2009 NHTS sample and so were dropped from the 2001 sample for consistency. Finally, diesel and electric vehicles were dropped (1.4\% and $3.4 \%$ of the sample respectively). The results with these assumptions relaxed are similar to the main results and are available upon request.

${ }^{4}$ NHTS collected VMT data through (i) direct questioning; (ii) estimations based on odometer readings (only for 2001 NHTS); and (iii) estimations based on travel diaries. NHTS data reports two different measures of VMT, "reported VMT" and "bestmiles." Reported VMT is based only on the direct survey questions. Bestmiles is based on regression techniques combining information from all three reporting techniques. Since, bestmiles requires more information, this variables had more missing values compared to VMT. Following Bento et al. (2009), we used reported VMT in our central estimates, using bestmiles
} 
data to which we had access provides more specific geographic data on each household than the public version, down to its zip code.

To each household, we match quarterly gasoline prices in the household's metropolitan statistical area (MSA) at the time of the NHTS survey. Using contemporary gasoline prices, rather than longer-term averages, is appropriate if households assume gasoline prices follow a random walk, so that current prices represent the best long-term forecast. In previous work, Bento et al. (2009), Berry et al. (1995), Gillingham (2012), and Goldberg (1995) all assume that prices follow a random walk and that only current prices matter. David and Hamilton (2004) and Geman (2007) have shown that gasoline prices do actually follow a random walk. Li, Timmins, and von Haefen (2009) also find the lagged gasoline prices have little impact on purchasing decisions. Finally, Anderson et al. (2011) and Anderson, Kellogg, and Sallee (2013) provide empirical evidence suggesting that on average expected real gasoline prices as reported in surveys are equal to current prices. Moreover, because our model focuses as much on the decision to hold an existing car or re-optimize when gas prices change, matching at the time of the survey is more appropriate than matching at the purchase time.

Spatially, ACCRA provides gasoline prices for more than 300 MSAs. Using the geographical indicators of the NHTS data, we matched these prices to each household in the NHTS datasets, using the US Department of Housing and Urban Development (HUD) USPS ZIP Code Crosswalk Files. ${ }^{5}$ Gasoline prices are converted to 2009 dollars using the Consumer Price Index (CPI).

wherever reported VMT is missing. As sensitivity analyses, we also considered using only reported VMT or only bestmiles. Our results are qualitatively similar when using those data instead.

${ }^{5}$ For households in the NHTS outside these 300 metropolitan areas, we used NHTS-reported gasoline prices. The NHTS prices are at a more aggregate geographic level, namely Petroleum Administration for Defense Districts (PADDs). These districts are similar to Census regions in that each state is assigned to a given region, but the regions are drawn up in such a way as to maximize gasoline distribution. ACCRA 
Finally, the fuel economy data was obtained from the Department of Energy's website www.fueleconomy.gov. This website provides the fuel economy data by vehicle make, model and year and these variables were used to match the vehicle fuel economy with the NHTS data. ${ }^{6}$

Table 1 provides summary statistics of household responses in the NHTS. The first column reports the descriptive statistics for the entire sample. This is broken down by NHTS survey years in columns 2 and 3, respectively. Column 4 compares columns 2 and 3 and reports the differences and standard errors in parentheses. Table 1 shows that the average real gasoline price increased from $\$ 1.63$ in 2001 to $\$ 3.14$ in 2009 . Moreover, the heterogeneity in gasoline prices increased, with the standard deviation increasing from 0.21 to 0.67 . One reason for this is major fluctuations in gasoline prices during the 2008-2009 period. Gasoline prices continued to increase during the first two quarters of 2008, reaching a peak of $\$ 4.60$ and then started to decline before escalating again in the beginning of 2009. Panel A in Figure 2 shows the kernel densities of (real) gasoline prices for the two survey years. It shows very little overlap in the distributions, with the 2009 distribution being both higher and more diffuse. Panel B of Figure 2 plots within-MSA average gasoline prices in 2009 against their equivalent in 2001. The figure shows that there is a good deal of between-MSA variation in changes in gasoline prices, as well as both cross-sectional and temporal variation in levels of gasoline prices. These within-city changes represent the essential variation in gas prices that we exploit in our difference-in-differences framework.

Along with this increase in gasoline prices, Table 1 shows that average VMT declined

and NHTS gasoline prices are highly correlated. We regressed ACCRA gasoline prices on NHTS gasoline prices and used predicted gasoline prices for those NHTS MSAs that could not be matched with ACCRA data.

${ }^{6}$ We use a combined MPG which is a weighted average based on the standard assumption (used by the US EPA and others) that the automobile was operated 55\% under city driving conditions and $45 \%$ under highway conditions. 
about $10 \%$ and average MPG improved by about $1 \%$. Figure 3 plots the distribution of annual VMT and MPG for both surveys. The figure illustrates the slight leftward shift in the distribution of VMT over time and little detectable change in that for MPG.

\section{Results}

\section{A. Patterns in the Raw Data}

We begin our analysis of the matching effect by looking at patterns in the raw data. Because of the large changes in gas prices between 2001 and 2009, a simple starting point is to compare the patterns in those two cross sections. In Figure 4 Panel A, the expected value of miles per gallon (MPG) conditional on VMT is plotted for the years 2001 and 2009 using linear regression. Overlayed on each plot is a similar counter-factual plot of what the relationship would look like if, given the actual distribution of VMT and the actual composition of the fleet in each year, there were perfectly assortative matching, so that the lowest-VMT individual had the lowest MPG (highest GPM) car, etc. The figures show that the observed assignment is far from perfectly assortative. A shift from the empirical relationship to perfect matching is one way to gauge the potential for the matching effect. If household demand for VMT and vehicle fuel efficiency were perfectly matched in 2009, gasoline consumption would have been $15 \%$ lower, even with no change in the composition of the fleet and no change in individuals' utilization.

However, our hypothesis does not center on how strong the matching effect should be in any particular cross section. Rather, our hypothesis is that when gas prices are higher, the matching effect should be stronger. Since gas prices increased from an average of $\$ 1.63$ per gallon in 2001 to $\$ 3.14$ in 2009 (in real terms), we would expect more assortative matching over time. The raw data reveal this pattern. Figure 4 Panel A shows that, between 2001 and 2009, as gasoline prices increased, the relationship between these two variables went from slightly decreasing to slightly 
increasing. (The small change is consistent with our findings, reported below, of a statistically significant change in slope of about 0.02 , which still has meaningful effects on gas consumption.) Panel B displays the CDF of car fuel economy among individuals in the highest quartile of VMT and lowest quartile of VMT, for 2001 and 2009 respectively. It shows that in 2001, the distribution of MPG among the lowest VMT quartile actually first-order stochastically dominated the distribution among the highest quartile. That is, the low utilization types had cars with better gas mileage than the high utilization types. This is consistent with the downward slope in Panel A for 2001. In 2009, when gas prices were higher, the situation reverses, with the distribution of MPG among the highest VMT quartile first-order stochastically dominating the distribution among the lowest quartile. This is consistent with the upward slope in Panel A for 2009. The switch from 2001 to 2009 in these patterns is consistent with our hypothesis, with high utilization types being more likely to have cars with better gas mileage when gas prices are high.

Finally, we exploit the intertemporal and spatial variation in the data to analyze the changes in sorting correlations between the two survey waves. First, we calculate the correlations between VMT and MPG within each MSA-survey-wave period as an aggregate summary of matching. Second, we measure the changes in these city-specific correlations between the two survey years and correlate them with city-specific changes in gasoline prices over the waves. A scatter plot and an estimated weighted regression line that depicts the relationship between these two changes are presented in Figure 5. The slope of the regression line is 0.07 and is significant at the $5 \%$ level. In other words, MSAs where gasoline price changes were larger also had relatively higher increases in the correlation between VMT and MPG. This is consistent with our prediction of more assortative matching. 


\section{B. OLS}

While such patterns in the raw data between 2001 and 2009 are suggestive, other changes in the economic environment between those years could be important. Accordingly, we primarily rely on difference-in-differences models with year and MSA dummies. As noted in the previous section, our base model uses OLS to estimate these effects. Table 2 shows the results of this model under different variants of Equation (6). The first column of the table only includes the main effects of VMT (in thousands of miles) and gasoline prices as well as their interaction. The interaction between VMT and gasoline prices represents the matching effect, that is, the change in correlation between MPG and VMT when gasoline prices increase. Standard errors clustered by state are reported in parentheses. The second column adds MSA dummies to control for time-invariant unobservables between the survey years, such as the availability of mass transit, urban sprawl (Bento et al. 2005), and differences in average demands across cities. The third column adds year dummies to control for national time-varying effects. These could include the change in the fleet composition between years, other technological changes, changes in lifestyle and preferences, changes in commuting patterns, and so forth. Columns 4-6 parallel the first three specifications, but with the addition of household-level controls. These controls include number of household members, number of adults in the households, number of workers in the household, the fraction of children (age $<18$ ) and women in the household, and household income quartiles. Column 6 represents Equation (6) as it is written and is our preferred specification. The seventh column replaces the MSA and year dummies with MSA-month dummies. This specification controls for unobserved timevarying economic conditions in the city, which might be correlated with gas prices, including changes in income or changes in geographic sorting patterns (Molloy and Shan 2013). Finally, the 
eighth column includes interactions between the demographic variables and gasoline prices, capturing additional heterogeneity in the effect of gasoline prices on VMT, beyond that already captured in the interaction with VMT. For all these regressions, the matching effect is positive and statistically significant and quite robust across specifications.

The results imply that as gasoline prices increase, households that drive more are driving a more fuel efficient vehicle relative to households that drive less. Specifically, the results of Table 2 indicate that, for a $\$ 1$ increase in gasoline prices, households choose cars with about 0.02 greater MPG per 1000 miles they drive. Holding constant the mean fleet MPG at 2001 levels, when gasoline prices increase from $\$ 1.63$ to $\$ 3.14$ the model predicts an individual driving 4,000 miles (at the $25^{\text {th }}$ percentile of VMT) switches on average from a car getting 25.3 MPG to one getting 25.4, while an individual driving 14,000 miles (at about the $75^{\text {th }}$ percentile) on average switches from a car getting 25.2 MPG to one getting 25.7. In other words, when gas prices increase, fuel-efficient cars are more likely to be allocated to high-VMT types, while inefficient cars are more likely to be allocated to low-VMT types, consistent with the matching effect. The negative coefficients on gas prices may at first be surprising (seemingly implying higher gas prices lower MPG), but recall that gas prices also enter in the interaction term; in fact, the marginal effect of gas prices is positive in all specifications at the mean of the data.

As noted previously, one potential concern with this model is the endogeneity of gasoline prices. Our preferred specification in column 6 includes year and MSA dummies. Thus, any endogeneity of gasoline prices would have to come from city-year shocks in the average demand for (or supply of) vehicle types that drive city-year variation in gasoline prices, after controlling for time-invariant city effects and city-invariant year effects. This seems unlikely. However, in column 7 we include city-month dummies. This removes all variation in gasoline price (in levels), so 
the mean residual in Equation (6) only relates to the individual's departure from the city-month average residual. Any city-time variation in average MPG that could affect gasoline prices is absorbed in the fixed effect. The results remain robust to this specification, indicating little concern about endogeneity of gasoline prices. Finally, we also consider instrumenting for gasoline prices in additional results presented below.

\section{Instrumenting for VMT}

A potentially more serious issue with the OLS model is that VMT may be endogenous to MPG. VMT should affect the MPG of the chosen car, but by the same token the MPG of the chosen car also affects VMT, either decreasing it through the comfort effect or increasing it through the GPM effect.

To overcome this simultaneity problem, we use a variety of instrumental variables strategies. Our first strategy is to use the interactions of demographics with gasoline prices as instruments for VMT. In particular, consider the following model:

$$
\begin{gathered}
M P G_{i c m t}=\alpha+\beta \text { Price }_{m t}^{g a s}+\gamma V M T_{i c m t}+\theta\left[\text { Price }_{m t}^{g a s} \times V M T_{i c m t}\right] \\
+\mathbf{x}_{i m t}{ }^{\prime} \boldsymbol{\delta}+\eta_{m 0}+\lambda_{t 0}+\varepsilon_{i c m t}, \\
V M T_{i c m t}=a_{1}+c_{1} \text { Price }_{m t}^{g a s}+\left[\text { Price }_{c t}^{g a s} \times \mathbf{x}_{i m t}\right]^{\prime} \boldsymbol{d}_{\mathbf{1}}+\mathbf{x}_{i m t}{ }^{\prime} \boldsymbol{b}_{\mathbf{1}}+\eta_{m 1}+\lambda_{t 1}+\mu_{i c m t 1} \\
\text { Price }_{m t}^{g a s} \times V M T_{i c m t}= \\
a_{2}+c_{2} \text { Price }_{m t}^{g a s}+\left[\text { Price }_{m t}^{g a s} \times \mathbf{x}_{i m t}\right]^{\prime} \boldsymbol{d}_{\mathbf{2}} \\
+\mathbf{x}_{i m t}{ }^{\prime} \boldsymbol{b}_{\mathbf{2}}+\eta_{m 2}+\lambda_{t 2}+\mu_{i c m t 2}
\end{gathered}
$$

where, $\mathbf{x}_{\text {imt }}$ is a vector of household characteristics. The interactions of these characteristics with gasoline prices serve as instruments. These characteristics are the same as those used as controls in the OLS model. ${ }^{7}$

\footnotetext{
${ }^{7}$ Thus, the interaction of household income quartile, number of household members, number of adults, number of workers, and fraction of children and women in the household with gasoline prices serve as
} 
The identifying assumptions of this strategy deserve some discussion. Note the level effects of $\mathbf{x}_{\text {imt }}$ are not excluded from the outcome equation, Equation (7). Thus, demographics are allowed to affect the choice of car. The identifying assumption is only that gasoline prices do not affect car choice differently for different demographic types except through VMT. Demographics do drive heterogeneity in VMT demand (at a given price), which in turn affects heterogeneous sensitivity of MPG to gasoline prices. All this is consistent with our model of WTP expressed in Equation (4), where individual demographics can affect the taste for car types at the extensive margin $f()$ as well as the WTP for travel conditional on car type $\pi(i, c, V M T)$, but the first order effect of gasoline prices on car demand only operate through VMT (as seen in the last term of the expression). Our first IV strategy effectively ignores the second order effects related to how heterogeneity in $\partial V M T^{*} / \partial$ Price ${ }^{\text {Gas }}$ (after conditioning on a level of $V M T^{*}$ ) feeds back on the optimal choice of MPG. This restriction is embedded in a number of other models of car demand as well, including Feng, Fullerton, and Gan (2013), Gillingham (2012), and Goldberg (1998).

Table 3 shows the results for Equation (7) of the IV model. Besides the endogenous VMT terms, the only controls in the first column of Table 3 are gasoline prices, predicted VMT and demographics. MSA and year dummies are added successively to columns 2 and 3. Finally, MSAmonth dummies are included in column 4, which eliminates variation in gasoline prices in levels. (The specifications follow the pattern in Table 2 but always include demographics.) The matching effect is again positive and statistically significant in all specifications. The effect in Table 3 ranges from 0.018 to 0.028 . Overall, the estimated matching effect is similar to the OLS estimates, indicating little concern about the potential endogeneity of VMT and MPG after conditioning on these

instruments for VMT and [VMT $\times$ Pricegas]. These variables were selected based on the household determinants of VMT established by the previous literature (Bento et al. 2009, Small and Van Dender 2007, Li et al. 2014). 
effects.

As noted previously, the above exclusion restrictions are motivated by our theoretical model, in which the heterogeneous effects of gasoline prices on MPG work only through heterogeneity in utilization. Nevertheless, it might be desirable to include interactions of demographics with gasoline prices in the outcome equation in other ways, beyond the utilization channel, for additional flexibility. For example, perhaps different demographic groups form different expectations about future gasoline prices or have differences in how salient gasoline prices are to them. To accommodate this possibility, we consider two very different alternative strategies. One is to add additional economic structure, with nonlinearities in the model that we can leverage for identification. The other strategy is simply to loosen the causal interpretation of VMT in the model and look at heterogeneous effects of prices as they are correlated with VMT.

Consider first the strategy to impose additional economic structure, and to leverage nonlinearities to identify heterogeneous effects of gasoline prices on MPG choice. If VMT is a nonlinear function of household characteristics, we can include Price $g_{m t}^{g a s} \times \mathbf{x}_{i m t}$ in Equation (7). We use a functional form consistent with the structural model of Bento et al. (2009), in which VMT and MPG are simultaneously determined and in which such nonlinearities arise through the economics of the model. Bento et al. (2009) use the following indirect utility function:

$$
V_{i c}^{\prime}=-\frac{1}{\lambda_{i}} \exp \left(-\lambda_{i}\left(\frac{Y_{i} / T_{i}-r_{i c}}{p_{i m t}^{x}}\right)\right)-\frac{1}{\beta_{i c}} \exp \left(\alpha_{i c}+\beta_{i c} \frac{p_{i c}^{M}}{p_{i m t}^{x}}\right)+\tau_{i c},
$$

where $\alpha_{i c}=\widetilde{\boldsymbol{\alpha}}_{i}^{\prime} \mathbf{z}_{i c}^{\alpha} ; \beta_{i c}=-\exp \left(\widetilde{\boldsymbol{\beta}}_{i}^{\prime} \mathbf{z}_{i c}^{\beta}\right) ; \lambda_{i}=\exp \left(\tilde{\boldsymbol{\lambda}}_{i}^{\prime} \mathbf{z}_{i c}^{\lambda}\right) ; \tau_{i c}=\tilde{\mathbf{\tau}}_{i}^{\prime} \mathbf{z}_{i c}^{\tau} ; r_{i c}$ is vehicle rental price; $p_{i c}^{M}$ is vehicle utilization price; $Y_{i}$ is the household income; $T_{i}$ is a fixed number of choice occasions set equal to the number of adults in the household plus one; and $p_{i m t}^{x}$ is the Hicksian composite 
commodity price. ${ }^{8} \mathbf{z}_{i c}^{\alpha}, \mathbf{z}_{i c}^{\beta}, \mathbf{z}_{i c}^{\tau}$ are vectors of automobile characteristics (age, make, class dummies) interacted with household demographics and $\mathbf{z}_{i}^{\lambda}$ are household characteristics. ${ }^{9}$ Using Roy's identity, VMT demand for household $i$ conditional on $\operatorname{car} c$ is:

$$
V M T_{i c}=\exp \left(\alpha_{i c}+\beta_{i c} \frac{p_{i c}^{M}}{p_{i m t}^{x}}+\lambda_{i}\left(\frac{Y_{i} / T_{i}-r_{i c}}{p_{i m t}^{x}}\right)\right)
$$

One can predict $\widehat{V M T}_{i c(i)}$ by using the above model, but $\widehat{V M T}_{i c(i)}$ still would be endogenous to MPG through the vehicle characteristics $\mathbf{z}$, which are simultaneously chosen. However, we instead can predict VMT of household $i$ at a fixed set of characteristics. In particular, for each household $i$, we predict VMT for each car type (i.e. make-model-year) $c$. We then take a weighted average of those VMTs, using the proportion of type $c$ in the sample as weights. Using this $\widehat{V M T}_{i \bar{c} m t}$ as an instrument, we then estimate the following model:

$$
\begin{aligned}
M P G_{i c m t}=\alpha & +\beta \text { Price }_{m t}^{\text {gas }}+\mathbf{x}_{i m t} \boldsymbol{\delta}+\left[\text { Price }_{m t}^{\text {gas }} \times \mathbf{x}_{i m t}\right] \boldsymbol{\rho}+\pi \widehat{V M T}_{i c m t} \\
& +\theta\left[\text { Price }_{m t}^{\text {gas }} \times \widehat{V M T}_{i c m t}\right]+\eta_{m}+\lambda_{t}+\varepsilon_{i c m t} \\
V M T_{i c m t}=a+ & b \widehat{V M T}_{i \bar{c} m t}+c \text { Price }_{m t}^{g a s}+\left[\text { Price }_{m t}^{g a s} \times \widehat{V M T}_{i \bar{c} m t}\right] d+\eta_{m}+\lambda_{t} \\
& +\mu_{i c m t}
\end{aligned}
$$

In Equation (13), VMT is a function of gasoline prices and $\widehat{V M T}_{i \bar{c} m t}$, the latter being computed from the model estimated by Bento et al. (2009) averaged over the automobile fleet. This variable is a highly non-linear function of demographics, including household members, household income

\footnotetext{
${ }^{8}$ If the number of adults is less than the number of household vehicles, $T_{i}$ equals the number of household vehicles. $p_{i m t}^{x}$ is computed using the ACCRA cost-of-living index for each year, with adjustments over time using the CPI.

${ }^{9}$ Bento et al. (2009) categorized households into twelve different strata based on employment status, average household age and the number and age distribution of children in the household. Vehicles are categorized by vehicle class. For more information, see Bento et al. (2009).
} 
quartile, number of children and women in the household, household age distribution, number of adults in the households, and vehicle class, vehicle age and driving cost per mile of the average vehicle. In Equation (12), we then estimate the main equation of interest using this constructed variable as an instrument for VMT. The matching effect is again given by $\theta$ : the coefficient associated with the interaction term between gasoline prices and $\widehat{V M T}_{i \bar{c} m t}$. The model given by Equations (12) and (13) overcomes the issues associated with the previous two models. An advantage of this particular model over the model given by Equations (7)-(9) is that now we can include Price $e_{m t}^{g a s} \times \mathbf{x}_{i m t}$ in the second-stage. These will capture heterogeneous effects of a change in gasoline prices on MPG.

Table 4 shows the results of the second stage of the IV model given by Equation (12)-(13). In the first column, only demographic controls are included. In the second and third columns, city and time dummies are successively added. In the fourth column, city-month dummies replace the city and year dummies. As with the previous model using linear instruments, the matching effect is positive and significant in all but the first model (with no controls). The point estimates are bigger than the previous models, but of the same magnitude. Overall then, these results are consistent with our previous estimates. In the last column, the interactions of demographic controls with gasoline prices, one of the chief motivations for using these instruments, are added. Unfortunately, the standard errors are much higher using this approach. Although the estimated point effect also is much larger than in the previous models, with the large standard errors for this model we cannot reject the earlier point estimates. It may be too great a challenge to separately identify heterogeneity across utilization types in the effect of gasoline prices on MPG from other such heterogeneity. 
As an alternative to this additional structure, we also consider a simple reduced form approach that measures the correlation between heterogeneity in the effect of gasoline prices on MPG and heterogeneity in VMT. Consider the following two equations:

$$
\begin{gathered}
M P G_{i c m t}=\alpha+\mathbf{x}_{i m t}{ }^{\prime} \boldsymbol{\beta}+\text { Price }_{m t}^{g a s}+\left[\text { Price }_{m t}^{g a s} \times \mathbf{x}_{i m t}\right]^{\prime} \boldsymbol{\theta}+\eta_{m 1}+\lambda_{t 1}+\varepsilon_{i c m t} \\
V M T_{i c m t}=a+\mathbf{x}_{i m t}{ }^{\prime} \boldsymbol{b}+c \text { Price }{ }_{m t}^{g a s}+\left[\text { Price }_{m t}^{g a s} \times \mathbf{x}_{i m t}\right]^{\prime} \boldsymbol{d}+\eta_{m 2}+\lambda_{t 2}+\mu_{i c m t} .
\end{gathered}
$$

Because the effects of VMT and $\mathbf{x}$ cannot be identified separately, Equations (14) and (15) represent reduced form regressions in which $\boldsymbol{\beta}$ and $\boldsymbol{\theta}$ (and $\boldsymbol{b}$ and $\boldsymbol{d}$ ) capture direct effects of demographics and effects through VMT (which is a linear function of demographics). MPG and VMT are simultaneously determined, so $E[\varepsilon \mu] \neq 0$, but because VMT does not appear in the reduced form equation for MPG, the equations can be estimated with OLS. Then, the estimated heterogeneous effects of price on MPG can be correlated with VMT, to see whether it is the highor low-VMT types that are more responsive to gasoline prices. In other words, we give up on identifying the heterogeneous effects of gasoline prices on MPG across utilization types per se, but still identify the heterogeneity across demographic groups, and we can see how those demographic groups are correlated with utilization.

To accomplish this one could take the following steps:

1. Estimate Equation (14) by OLS and let $\widehat{T}=\partial \widehat{M P G} / \partial P r i c e^{g a s}=\hat{\delta}+\mathbf{x}^{\prime} \widehat{\boldsymbol{\theta}}$ be the estimated treatment effect of a change in gasoline prices on MPG for a household with characteristics $\mathbf{x}$.

2. Estimate Equation (15) by OLS and let $\widehat{V M T}=\hat{a}+\mathbf{x}^{\widehat{b} \boldsymbol{b}}+\hat{c} \overline{\operatorname{Pr}_{\text {rce }} e^{g a s}}+\left[\overline{\text { Prlce }^{g a s}} \times \mathbf{x}\right]^{\prime} \widehat{\boldsymbol{d}}$, where $\overline{\text { Prlce }}{ }^{g a s}$ is the average gasoline price in the data. These are predicted household VMT at the average gasoline price. Average gasoline prices are used to isolate shifts in the demand curves of different utilization types, evaluated at the same price. 
3. To estimate the correlation between $\partial \widehat{M P G} / \partial$ Price gas and $\widehat{V M T}$, run the following regression:

$$
\widehat{T}=\pi_{0}+\pi_{1} \widehat{V M T}+\sigma,
$$

where the coefficient of interest is $\pi_{1}$.

As we show in Appendix B, this whole process is equivalent to estimating the following model:

$$
M P G_{i c m t}=\alpha+\beta \text { Price }_{m t}^{\text {gas }}+\mathbf{x}_{i m t}{ }^{\prime} \boldsymbol{\gamma}+\theta\left[\text { Price }_{m t}^{\text {gas }} \times \widehat{V M T}_{i c m t}\right]+\eta_{m}+\lambda_{t}+\varepsilon_{i c m t},
$$

where $\widehat{V M T}$ is the predicted VMT from Equation (15), but at average gasoline prices. The matching effect in Equation (17) is given by $\theta$. However, this strategy merely provides a correlation between the predicted VMT and the effect of Price ${ }^{\text {gas }}$.

The results for Equation (17) with corrected standard errors are shown in Table 5. The first column omits any controls except demographics. The second and third columns add MSA dummies and year dummies respectively. The fourth column includes MSA-month dummies. The estimated effects continue to be similar to the OLS and IV models, with a statistically significant matching effect (again in all but the first model) of roughly 0.017 to 0.021 . Thus, even if we cannot say that the causal effect is through utilization per se, we can say that the types of people who do drive more are allocated more fuel-efficient cars when gasoline prices are higher, relative to those who drive less. This reduced form correlation is enough to trigger the matching effect and to provide additional savings in fuel consumption when gasoline prices rise.

Figure 6 summarizes the results of these four models, using our preferred specification with year and city dummies and demographic controls. It shows the changing in the matching relationship predicted from various changes in gasoline prices $(\$ 0.25, \$ 0.55, \$ 1$, and $\$ 3.50)$. 


\section{Robustness Checks}

The above models all use miles per gallon as the dependent variable. Table 6 replicates the main results with gallons per mile as the dependent variable instead (in thousands). Thus, the coefficient estimates indicate the change in gasoline consumption (in thousands of gallons) per mile when there is a small change in the explanatory variables. The matching effect is negative for all the models, implying that when gasoline prices increase, a household that drives more drives a vehicle that consumes less gasoline, relative to a household than drives less. The bottom row of the table converts these estimates to an equivalent effect on MPG at the mean of the data. The results are generally similar to the corresponding estimates from the main tables, indicating little sensitivity to this change of specification. The matching effect corresponds to about 0.01 to $0.04 \mathrm{MPG}$ per dollar gasoline price per 1000 miles VMT.

We considered a variety of alternative models as well. In particular, we considered alternative measures of VMT as well as alternative ways of trimming the variable (see note 7 above). We also considered nominal gasoline prices instead of inflation-adjusted prices. For our IV models, we considered GMM estimation as well as two-stage least squares. In all models, we computed standard White heteroskedastic-robust standard errors as well as clustered standard errors. Our basic findings are unchanged with all these models, which are available upon request.

\section{E. Within- and Between-Household Matching}

Thus far, we have estimated the matching effect for all vehicles in the household. As noted previously, households with $N$ vehicles are treated as if they have $N$ exogenous bundles of trips which they then allocate to vehicles. Continuing with this assumption, we can focus just on within-household matching effects, in which we look at how such bundles are allocated to vehicles within the household under different gasoline prices. Figure 7 shows, on the vertical axis, the difference in 
MPG of the car allocated to the highest VMT bundle in the household relative to the lowest, plotted against the respective differences in VMT. Panel A does this for two-car households, Panel B for three-car households. (Notice some differences in VMT are quite large, but the left-hand side of the figure holds most of the density.) The figure shows that, in 2008-9, when gas prices averaged \$3.14, the difference is positive, meaning that the higher-MPG car was allocated to more VMT. Moreover, it is increasing in VMT especially on the left side which holds most of the data, indicating that as the split in miles between the two bundles of trips increases, the difference in MPG grows. In 2001-2, when gas prices averaged $\$ 1.63$, the difference was negative for two-car families and decreasing. For three-car households in 2001-2, the difference is close to zero with little trend. In either case, the difference is higher in 2008-9, when gas prices average $\$ 3.14$, than 2001-2. This suggests households match their high-MPG car to more VMT when gas prices are higher.

To further explore these within-household effects within a difference-in-differences framework, we repeat the OLS regression in Table 2, column 2 on multi-car households, but also include household fixed effects (which supersede MSA dummies and household demographics). We find a matching effect of 0.0362 , statistically significant at the $1 \%$ level. This effect is somewhat bigger than the effect using all the data, which is not surprising given that it would be easier to re-match vehicles to trips within a household than between households, as the latter requires a market transaction but the former does not. We view these results as suggestive, but caution that they depend on our simplifying assumption that we can take baskets of trips as exogenously determined prior to being matched to vehicles.

We similarly can focus on between-household effects by reducing the data set to one observation per household. This between-household analysis is interesting in itself, because it focuses 
on the transactions that take place as households sell old cars and buy new ones and the re-allocation that emerges. It has the further virtue of eliminating the necessity of our assumption about the exogenous division of trips within the household. We conduct such a between-household analysis three ways. Our preferred approach is to take the average MPG of all cars in the household, weighted by each car's VMT, to represent a household-level average MPG. Likewise, we take the total VMT of the household divided by the number of adults, to obtain the household's per-capita VMT. This approach removes within-household variation while giving some weight to all its decisions and makes no assumptions about how total VMT is allocated to cars. The results are displayed in Panel A of Table 7 (which for brevity shows only the coefficients from the matching effect). The columns correspond to our preferred specification (with year and MSA dummies and demographic characteristics) for the OLS, linear IV, IV with the non-linear instrument, and noncausal models respectively. The results remain similar to the previous findings, but slightly smaller, which is consistent with the idea that the transaction costs of re-matching to automobiles is more difficult between households than within them.

As an alternative to taking the household-level average, in Panel B we take only the car with the highest VMT in the household ("top car"). The results are similar to Panel A. This second approach has the advantage of using one one car but the disadvantage of taking the VMT assigned by multi-car households to the top car as exogenous. Finally, in Panel C, we take only one-car households. ${ }^{10}$ While this approach has the advantage of sidestepping the question of how VMT is allocated across cars, it has the disadvantage of created a more selected and less representative sample (as well as dropping over half the data). For example, the average one-car household has

\footnotetext{
${ }^{10} \mathrm{We}$ also include households in which the second car is effectively unused, with less than one thousand miles.
} 
1.9 people and drives 9,287 miles per year, whereas the average household in the data has 2.4 people and drives its top car 12,960 miles per year. Nevertheless, the estimates using this approach are similar to the other two approaches, except for the non-linear instruments, which were ineffective in this subsample (with the instruments failing to pass most tests of relevance).

\section{F. Gasoline Taxes}

Our analysis to this point has used variation in the overall price of gasoline. However, energy policies typically influence gasoline prices through gasoline taxes. Moreover, households might respond differently to gasoline taxes than other components of the price. For example, they might view them as more permanent than variation in oil prices or refinery costs or more salient. Speaking to this point, Li, Linn, and Muehlegger (2014) recently found that gasoline price elasticities are larger for changes in the gasoline tax than from other sources of variation in prices. ${ }^{11}$ They also found that the MPG of the average car responded more to taxes. This raises the possibility that the matching effect might also be stronger from changes in gasoline taxes than other price changes.

To further explore this issue, we gathered data on gasoline prices by state from the American Petroleum Institute's (API's) State Motor Fuels Tax Reports. These data are at the monthly level for 2008-9 (from which we constructed quarterly averages to match our quarterly gasoline price data) and the annual level for 2001-2. Weighting by our data, the average gasoline tax increased 6 cents between survey waves. The variability ranged from increases of more than 10 cents in Texas, Oregon, and Maine to small decreases in Virginia and California.

Following Li, Linn, and Muehlegger (2014), we then reran our OLS models using both

\footnotetext{
${ }^{11}$ Coglianese et al. (2016) have argued that taxes are an inappropriate instrument for gas prices when estimating very short-term gasoline demand elasticities, if households tank up in anticipation of tax hikes. However, this critique would not apply to our setting of year-to-year or changes in automobile fuel economy choices.
} 
variation in gasoline taxes and net-of-tax price variation. This approach allows us to separately identify the two effects. As an alternative, we continue to employ our basic model with gasoline prices in the equation of interest, but instrument for gasoline prices with gasoline taxes. This approach obviously limits the source of variation in the data to the taxes. ${ }^{12}$

Panel A of Table 8 shows the results of the first approach, in which we separately estimate the effects of gasoline taxes and net-of-tax gasoline prices, showing only the respective matching effects. The estimates suggest the effect of the gasoline tax is three times the effect of prices generally, with a statistically significant matching effect of about 0.06 (versus about 0.02 in our previous models). Net-of-tax prices have a slightly smaller effect than the over-all price effect, of about 0.019 . (Note because these are a much larger share of overall prices they need not move as much from the overall effect.) Panel B shows the results in which we instrument for gasoline prices using gasoline taxes. The point estimates using this approach range from 0.03 to 0.04 , still higher than our earlier estimates of about 0.02 using raw gasoline prices. The findings from both panels are consistent with the notion that gas taxes are more salient than other shocks and with previous results from Li, Linn, and Muehlegger (2014). They also suggest that gasoline taxes can have a more potent effect than our earlier estimates using only gas prices would suggest.

\section{G. Implications}

In the introduction, we noted that an increase in gasoline prices should have three effects: a utilization effect on VMT, a compositional effect on the average fuel economy of the fleet, and a matching effect. Our model does not estimate the utilization effect, but does capture a combination

\footnotetext{
${ }^{12}$ We also considered instrumenting for VMT using the above strategies, however, the presence of multiple nonlinear endogenous variables (for the first strategy, VMT interacted with taxes and VMT interacted with net-of-tax prices; for the second, VMT interacted with gasoline prices with both treated as endogenous) made it impossible to identify all the structural effects without additional instruments.
} 
of a city-level composition effect and matching effect. It also provides a way to isolate the matching effect. Using our model, the change in household fuel economy due to a change in gasoline prices is given by $\partial M P G_{j} / \partial P^{\text {gas }}=\hat{\beta}+\hat{\theta} V M T_{j}$, where $\hat{\beta}$ and $\hat{\theta}$ are the estimated parameters on Price and Price*VMT respectively. The proportion of the change in gasoline consumption through the matching channel can be measured by Equation (18):

$$
\begin{gathered}
\text { Proportion of predicted total change } \\
\text { from matching effect }
\end{gathered}=1-\left(\frac{\sum_{j}\left(\frac{V M T_{j}}{\overline{M P G}_{j}+\hat{\beta}+\hat{\theta} \cdot \overline{V M T}}-\frac{V M T_{j}}{\overline{M P G_{j}}}\right)}{\sum_{j}\left(\frac{V M T_{j}}{\overline{M P G}_{j}+\hat{\beta}+\hat{\theta} \cdot V M T_{j}}-\frac{V M T_{j}}{\overline{M P G_{j}}}\right)}\right),
$$

where $\frac{V M T_{j}}{M P G_{j}}$ measures the gasoline consumption of vehicle $j$ and $\overline{V M T}$ is the average VMT.

Using our preferred specification with MSA and year dummies and demographic controls, we predict that a $\$ 1$ increase in gasoline taxes would result in a savings of $1.5 \%$ of US gasoline consumption in the short run from the matching affect alone, or 1.9 billion gallons annually. ${ }^{13}$ This compares to a short-run (one-year) savings of $7.2 \%$ from the composition effect estimated by $\mathrm{Li}$, Timmins, and von Haefen (2009). ${ }^{14}$ Although smaller that this estimate of the composition effect, the matching effect is economically meaningful. These gasoline savings correspond to 84 million metric tonnes of $\mathrm{CO}_{2}$ annually. Using the US social cost of carbon of $\$ 36 /$ tonne and Parry and Small's (2005) estimate of $\$ 0.16 /$ gallon of damages from conventional pollution, these gasoline savings are equivalent to $\$ 3.3$ billion in benefits from avoided pollution per year, just through the matching channel-i.e., with no change in the automotive fleet and no change in total miles driven.

\footnotetext{
${ }^{13}$ As the models are linear in prices, the effects of smaller changes in taxes can be computed as any proportion of \$1. Similarly, if one prefers to use the estimates from prices in Tables 2-4 rather than the effect of taxes, one could proportionately adjust these effects by about one-fourth to one-half.

${ }^{14}$ To compute this figure, we used their short run elasticity of MPG of 0.022 combined with the percentage change in each household's gas price associated with $\$ 1$ (adjusted for the difference in dollars).
} 
Moreover, these short-run effects are likely to be lower bounds on the long-run effects.

\section{Conclusion}

Combustion of gasoline has detrimental environmental and health impacts. To reduce these effects, one policy tool is to increase gasoline prices. Two effects of gasoline prices have been identified in the literature, the utilization effect and the compositional effect. The former implies that an increase in gasoline prices results in a decrease in the demand for VMT. The latter suggests that it causes an evolution of fleet towards fuel efficiency. As we have shown in this paper, there is a potential third effect of gasoline prices that has been overlooked in the previous studies. Due to heterogeneity in demand for VMT, increase in gasoline prices should particularly affect vehicle choices of households that drive more. In the presence of higher gasoline prices, the costs borne by high-VMT households is greater and hence they become more to outbid low-VMT households for a fuel efficient vehicle. In equilibrium, there will be matching of fuel efficiency among highVMT households and fuel inefficiency among low-VMT households. This is the first study that analyzes such assortative behavior.

To understand the potential importance of the matching effect, if fuel economy was assigned perfectly to households based on their VMT demand, US gasoline consumption would be $15 \%$ lower, without changing the fleet or VMT. Our study exploits variation in gasoline prices in the last decade to estimate how gasoline prices affect vehicle choice. Using our model based on taxes and our preferred specification, if gasoline taxes were $\$ 1$ higher, gasoline consumption would have been about $1.5 \%$ lower due to the matching effect alone. These additional benefits of higher prices further favor price-based policies. 


\section{REFERENCES}

Allcott, Hunt, and Nathan Wozny. 2016. "Gasoline Prices, Fuel Economy, and the Energy Paradox." Review of Economics and Statistics 96(5):779-95.

Anderson, Soren T., Ryan Kellogg, and James M. Sallee. 2013. "What Do Consumers Believe About Future Gasoline Prices?" Journal of Environmental Economics and Management 66: 383-403.

Anderson, Soren T., Ryan Kellogg, James M. Sallee, and Richard T. Curtin. 2011. "Forecasting Gasoline Prices Using Consumer Surveys." American Economic Review 101(3):110-14.

Austin, David, and Terry Dinan. 2005. "Clearing the air: The Costs and Consequences of Higher CAFE Standards and Increased Gasoline Taxes." Journal of Environmental Economics and management 50(3): 562-82.

Bento, Antonio M., Maureen L. Cropper, Ahmed Mushfiq Mobarak, and Katja Vinha. 2005. "The Effects of Urban Spatial Structure on Travel Demand in the United States." Review of Economics and Statistics 87: 466-78.

Bento, Antonio M., Lawrence H. Goulder, Mark R. Jacobsen, and Roger H. von Haefen. 2009. "Distributional and Efficiency Impacts of Increased US Gasoline Taxes." American Economic Review 99(3): 667-99.

Berry, Steven, James Levinsohn, and Ariel Pakes. 1995. "Automobile Prices in Market Equilibrium." Econometrica 63(4): 841-890.

Brown, Jennifer, Justine Hastings, Erin T. Mansur, and Sofia B. Villas-Boas. 2008. "Reformulating Competition? Gasoline Content Regulation and Wholesale Gasoline Prices." Journal of Environmental Economics and Management 55(1): 1-19.

Busse, Meghan R., Christopher R. Knittel, and Florian Zettelmeyer. 2013. "Are Consumers Myopic? Evidence from New and Used Car Purchases." American Economic Review 103(1): $220-56$.

Coglianese, John, Lucas W. Davis, Lutz Killian, and James H. Stock. 2016. "Anticipation, Tax Avoidance, and the Price-Elasticity of Gasoline-Demand." Journal of Applied Econometrics 32: 1-15.

Currie, Janet, Joshua G. Zivin, Jaime Mullins and Matthew Neidell. 2014. "What Do We Know About Short and Long Term Effects of Early Life Exposure to Pollution?" Annual Review of Resource Economics 6: 217-247.

Davis, Michael C., and James D. Hamilton. 2004. "Why Are Prices Sticky? The Dynamics of Wholesale Gasoline Prices." Journal of Money, Credit, and Banking 36: 17-37.

Davis, Lucas, and Lutz Kilian. 2011. "Estimating the Effect of a Gasoline Tax on Carbon Emissions." Journal of Applied Econometrics 26(7): 1187-1214. 
Dubin, Jeffrey A., and Daniel L. McFadden. 1984. "An econometric analysis of residential electric appliance holdings and consumption." Econometrica 52: 345-362.

Feng, Ye, Don Fullerton, and Li Gan. 2013. "Vehicle Choices, Miles Driven, and Pollution Policies." Journal of Regulatory Economics 44(1): 4-29.

Geman, Hélyette. 2007. "Mean Reversion Versus Random Walk in Oil and Natural Gas Prices." In M. Fu, R. Jarrow, J. Yen, and R. Elliott, eds. Advances in Mathematical Finance. Birkhauser: Boston, 219-228.

Gillingham, Kenneth. 2012. "Selection on Anticipated Driving and the Consumer Response to Changing Gasoline Prices." Mimeo.

Gillingham, Kenneth, Matthew J. Kotchen, David S. Rapson and Gernot Wagner. 2013. "Energy Policy: The Rebound Effect is Overplayed." Nature 493: 475-476.

Goldberg, Pinelopi Koujianou. 1995. "Product Differentiation and Oligopoly in International Markets: The Case of the US Automobile Industry." Econometrica 63(4): 891-951.

Goldberg, Pinelopi Koujianou. 1998. "The Effect of Corporate Average Fuel Efficiency Standards in the US." Journal of Industrial Economics 46(1): 1-33.

Graham, Daniel J., and Stephen Glaister. 2002. "The Demand for Automobile Fuel: A Survey of Elasticities." Journal of Transport Economics and Policy 36(1): 1-26.

Hughes, J.E., Christopher R. Knittel, and Daniel Sperling. 2008. "Evidence of a Shift in the Short-Run Price Elasticity of Gasoline Demand." The Energy Journal 29(1): 113-134.

Jacobsen, Mark R. 2013. "Evaluating US fuel economy standards in a model with producer and household heterogeneity." American Economic Journal: Economic Policy 5(23): 148-87.

Klier, Thomas, and Joshua Linn. 2010. "The Price of Gasoline and the Demand for Fuel Efficiency: Evidence from Monthly New Vehicle Sales Data." American Economic Journal: Economic Policy 2(3): 134-53.

Klier, Thomas, and Joshua Linn. 2011. "Corporate Average Fuel Economy Standards and the Market for New Vehicles." Annual Review of Resource Economics 3: 445-62.

Li, Shanjun, Christopher Timmins, and Roger H. von Haefen. 2009. "How Do Gasoline Prices Affect Fleet Fuel Economy?" American Economic Journal: Economic Policy 1(2): 11337.

Li, Shanjun, Joshua Linn, and Erich Muehlegger. 2014. "Gasoline Taxes and Consumer Behavior." American Economic Journal: Economic Policy 6(4): 302-42.

Linn, Joshua. 2016. "The Rebound Effect for Passenger Vehicles." Energy Journal 37(2): 25788. 
Molloy, Raven, and Hui Shan. 2014. "The Effect of Gasoline Prices on Household Location." Review of Economics and Statistics 95: 1212-21.

OECD. 2014. Consumption Tax Trends 2014. http://www.oecd-ilibrary.org/taxation/consumption-tax-trends-2014_ctt-2014-en

Parry, Ian W.H., and Kenneth A. Small. 2005. "Does Britain or the United States Have the Right Gasoline Tax?" American Economic Review 95(4): 1276-89.

Puller, Steven L., and Lorna A. Greening. 1999. "Household Adjustment to Gasoline Price Change: An Analysis Using 9 years of US Survey Data." Energy Economics 21: 37-52.

Sallee, James M., Sarah E. West, and Wei Fan. 2016. "Do Consumers Recognize the Value of Fuel Economy? Evidence from Used Car Prices and Gasoline Price Fluctuations." Journal of Public Economics 135: 61-73.

Small, Kenneth A., and Kurt Van Dender. 2007. "Fuel Efficiency and Motor Vehicle Travel: The Declining Rebound Effect." Energy Journal 28(1): 25-52.

United States Department of Energy (US DOE). 2011. Fuel Taxes by Country. http://www.afdc.energy.gov/data/10327. Last accessed 11 July, 2016.

West, Jeremy, Mark Hoekstra, Jonathan Meer, and Steven L. Puller. 2016. "Vehicle Miles (not) Traveled: Fuel Economy Requirements, Vehicle Characteristics, and Household Driving." Journal of Public Economics 145: 65-81. 
Figure 1: The Matching Effect

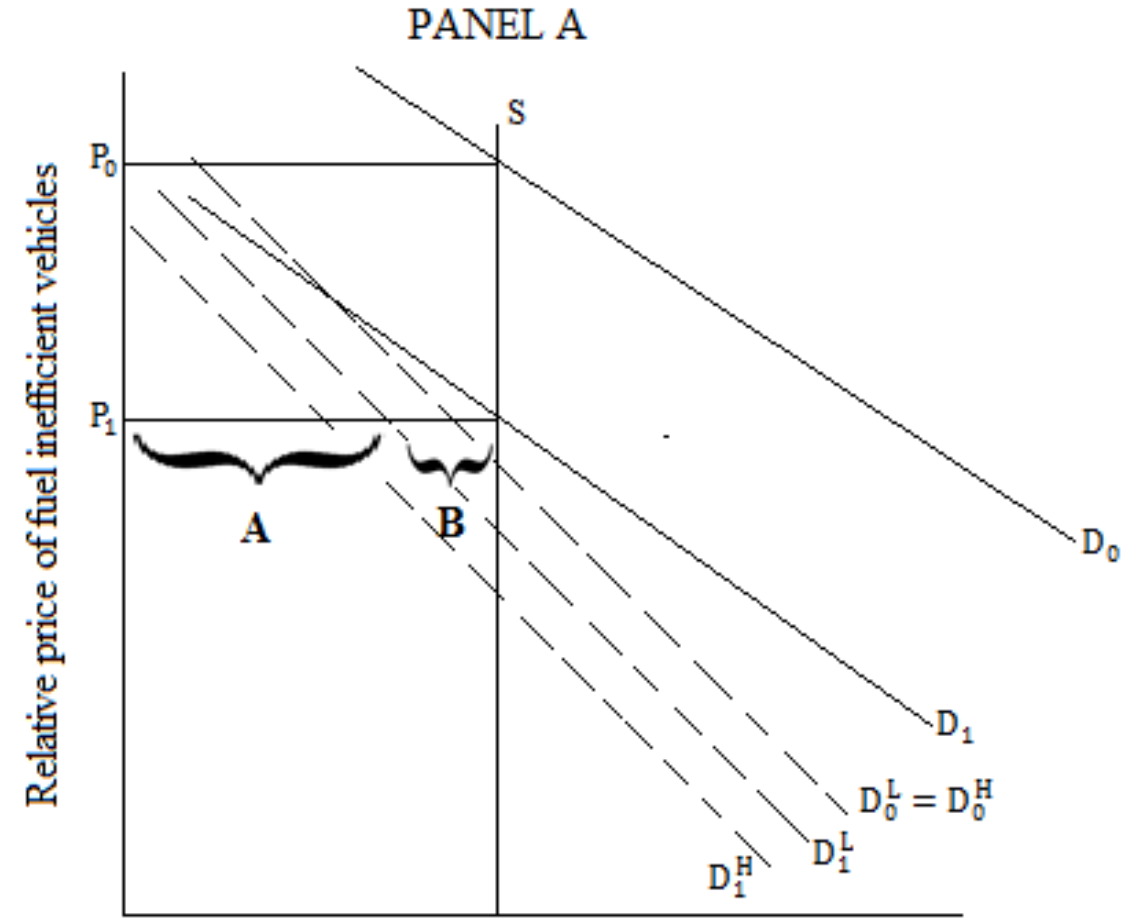

Fuel inefficient vehicles

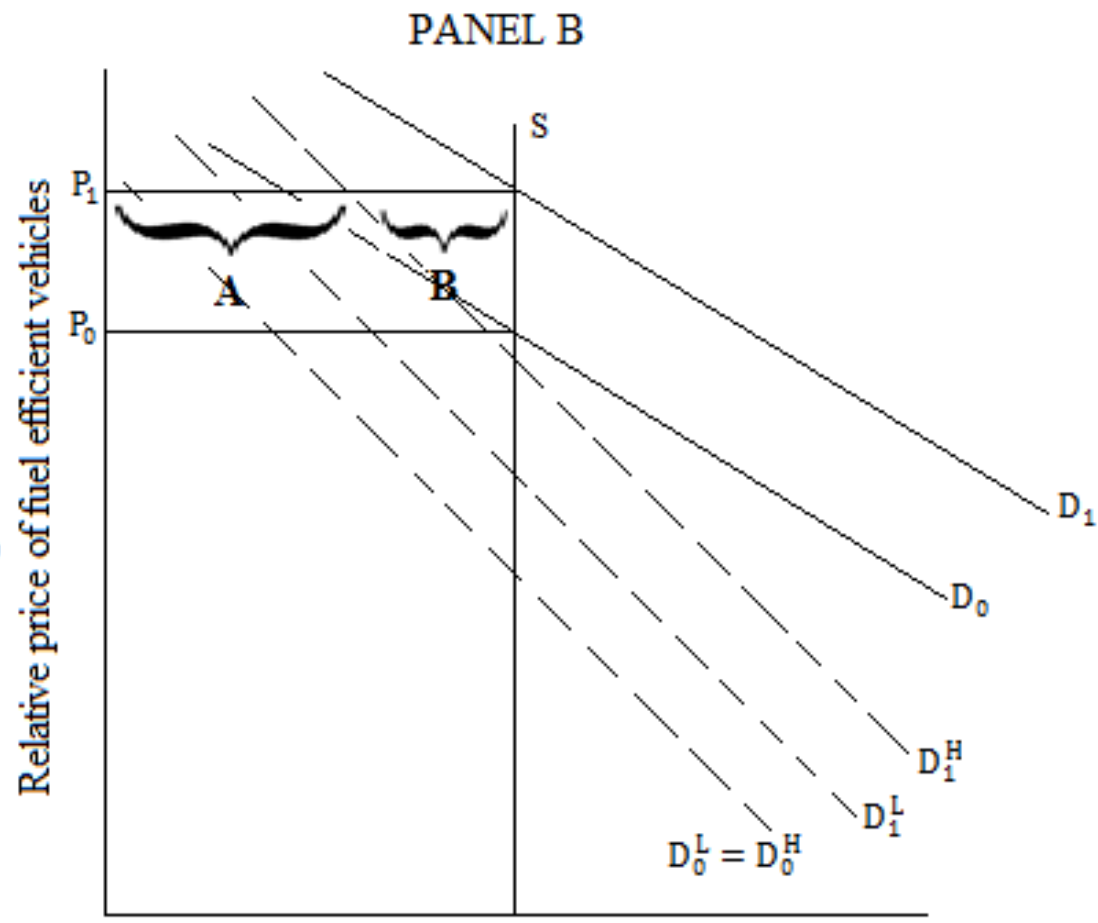

Fuel efficient vehicles

Notes: In these diagrams partial-equilibrium models illustrate the matching effect. There are two types of households: high-VMT (Hand low-VMT $(L)$. There are two types of vehicles: high- and low-GPM. The demand curves $D^{H}$ and $D^{L}$ show the relative willingness to pay (WTP) of the two household types for different fuel economies. In both panels above, the baseline case is given by a scenario where $D_{0}^{H}=D_{0}^{L}$ and the baseline market demand curve is given by $D_{0}$ for a relative price $P_{0}$. After an increase in gas prices, the relative WTP for inefficient vehicles decreases. The new market demand curve is shown by $D_{1}$ for a relative price $P_{1}$. However, due to the heterogeneity in demand among agents for VMT, the decrease (increase) in the relative WTP for the high-VMT types for inefficient (efficient) vehicles is greater than for the low-VMT types. 
Figure 2: MSA 2009 Gasoline Prices v. 2001 Gasoline Prices (in 2009 Dollars)

\section{Panel A: Gasoline Prices Kernel Densities}

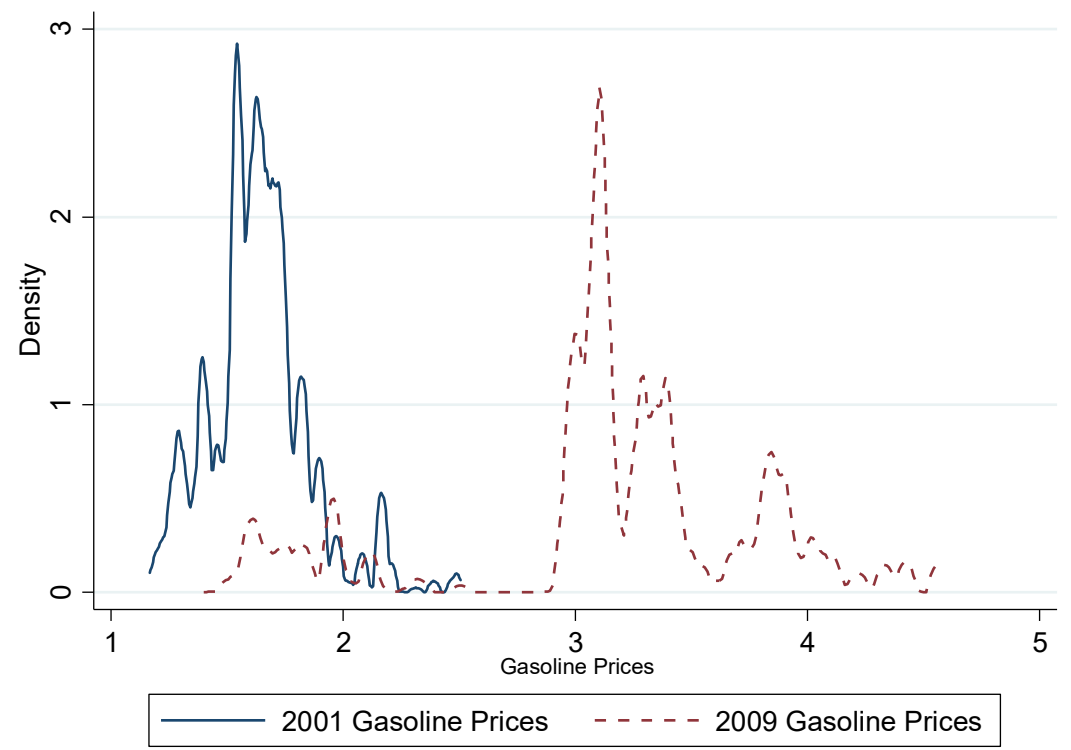

Panel B: 2009 Prices against 2001 Prices

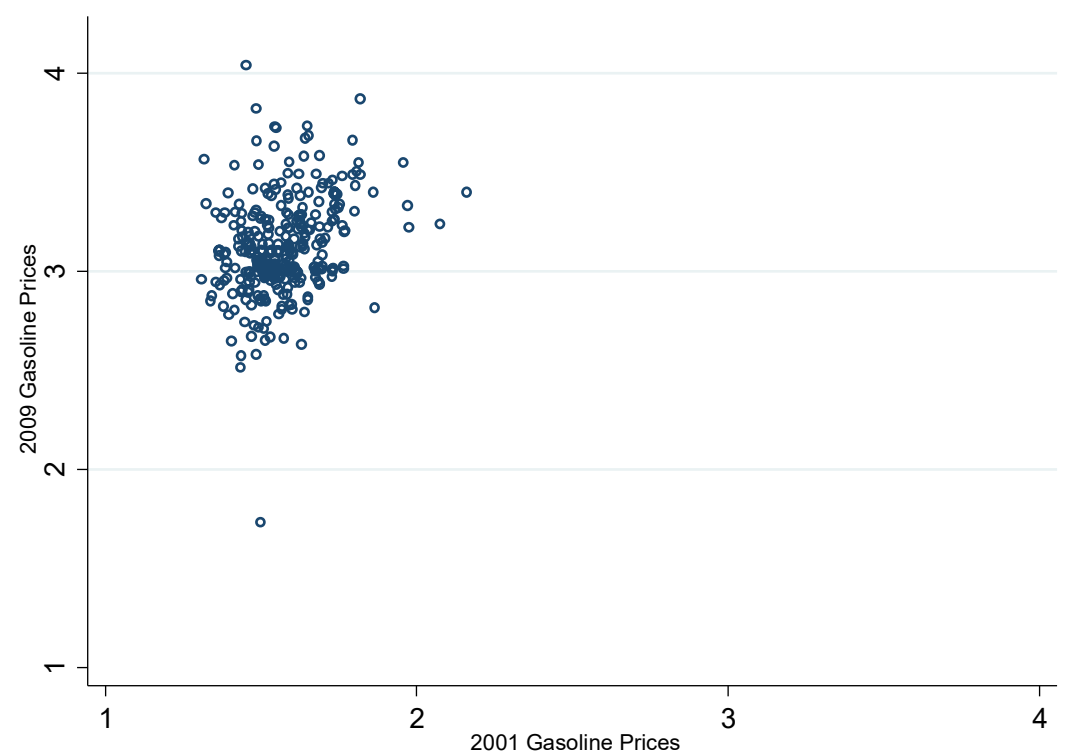

Notes: The graph in Panel A shows the kernel densities of gasoline prices for the 2001 (solid line) and the 2009 (dashed line) ACCRA gasoline prices. Panel B plots 2009 average MSA gasoline prices against 2001 average MSA gasoline prices. 


\section{Figure 3: Kernel densities of VMT and MPG}
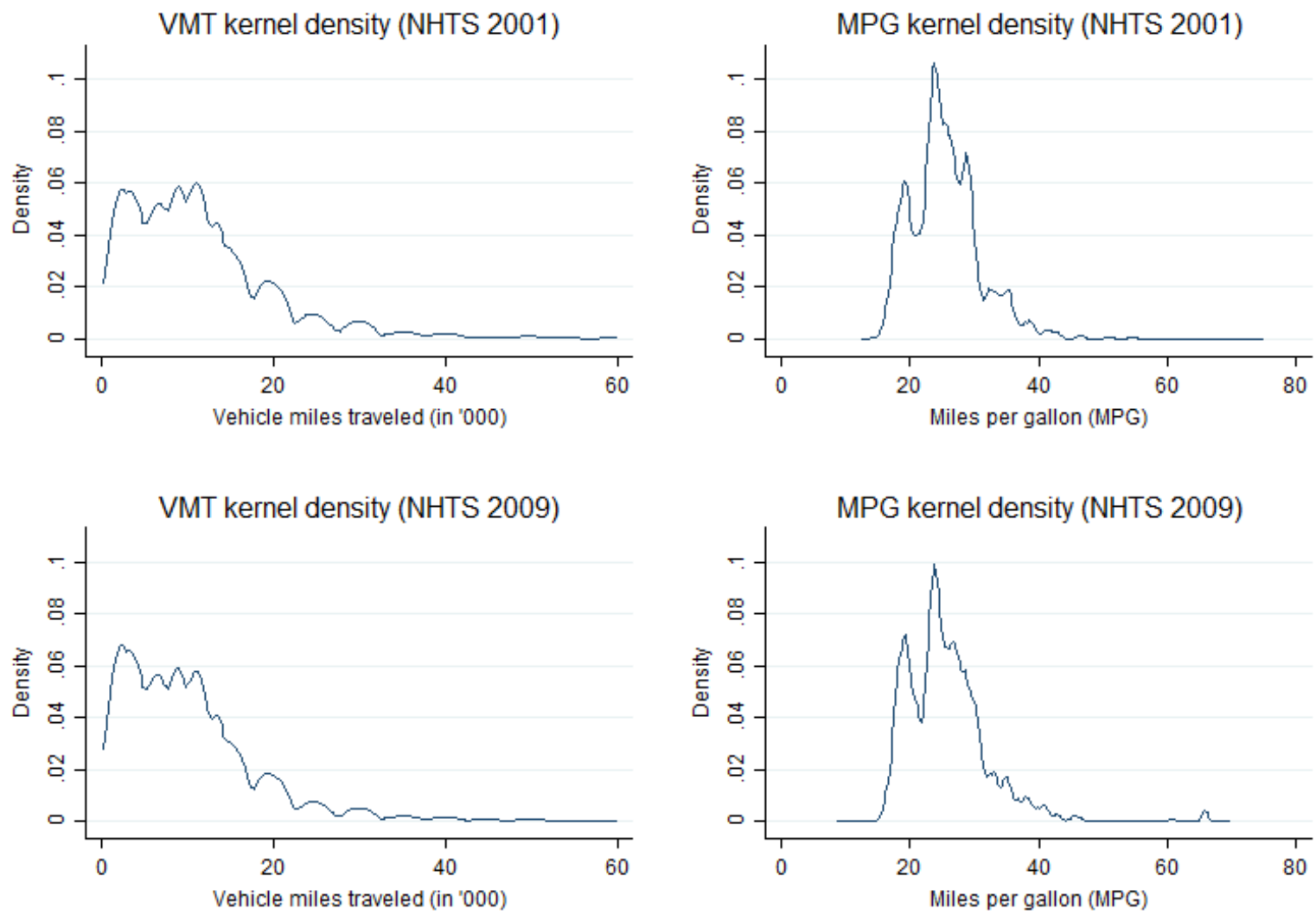

Source: 2001 \& 2009 NHTS and Department of Energy

Notes: These graphs show the kernel densities of reported vehicle miles traveled (VMT) in thousands and miles per gallon (MPG) per vehicle for the 2001 and the 2009 National Household Travel Survey (NHTS). 


\section{Figure 4: Is there a matching effect?}

Panel A. Matching in Raw Data vs. Perfect Matching, 2001 and 2009
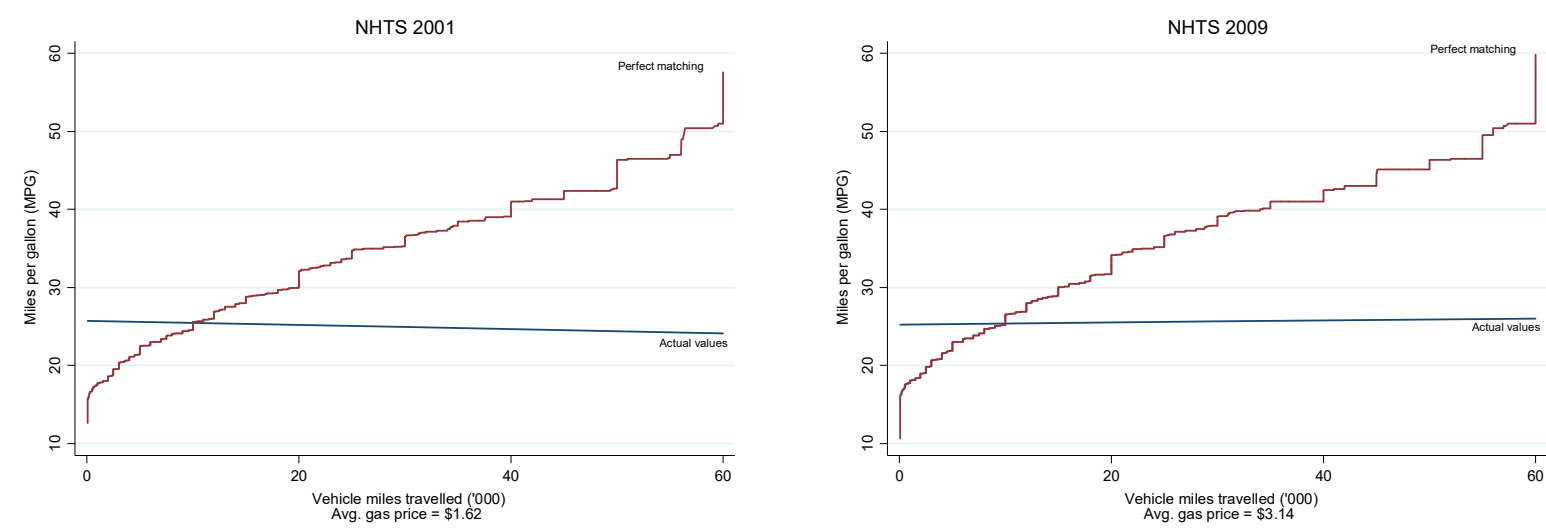

Panel B. CDF of MPG, by Top and Bottom VMT Quartile, 2001 and 2009
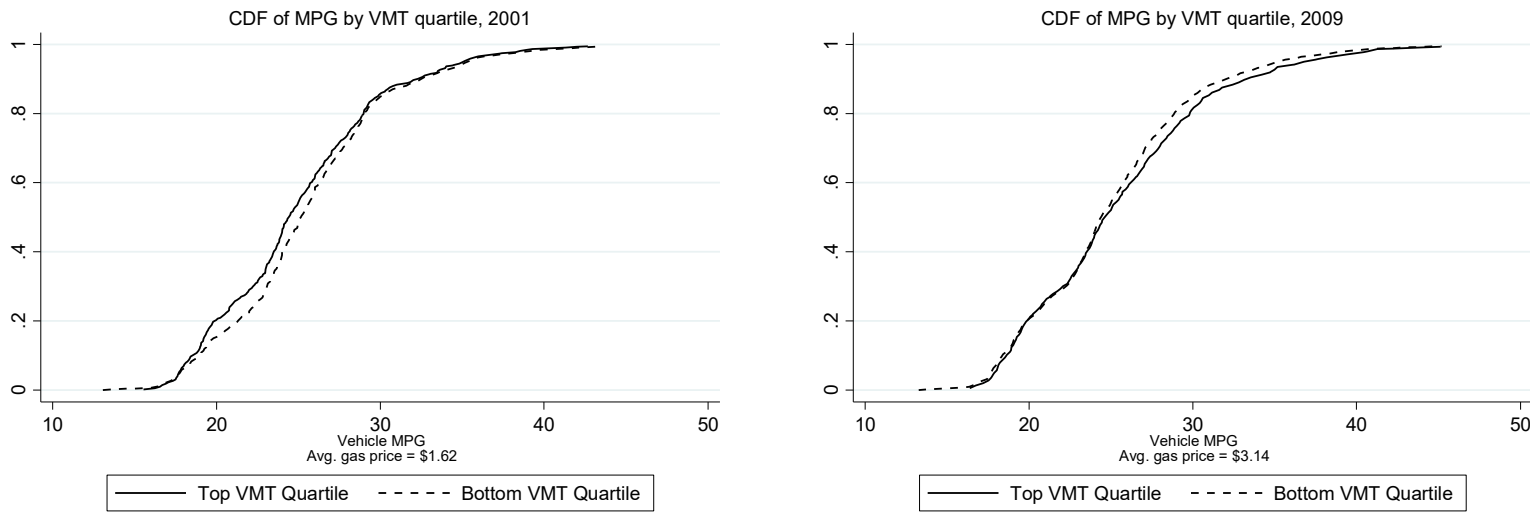

Notes: In Panel A, actual values in both graphs represent a linear regression of fuel economy on vehicle miles traveled (VMT). For perfect matching, vehicles were re-assigned to households based on their respective VMT, so that their ranks are the same. Panel B shows the distribution of fuel economy among those in the highest and lowest quartile of VMT. In 2001 low-VMT households have more fuel-efficient cars than high-VMT households (in the sense of first-order stochastic dominance of the distribution); in 2009 , the reverse is true. 
Figure 5: Change in sorting correlations

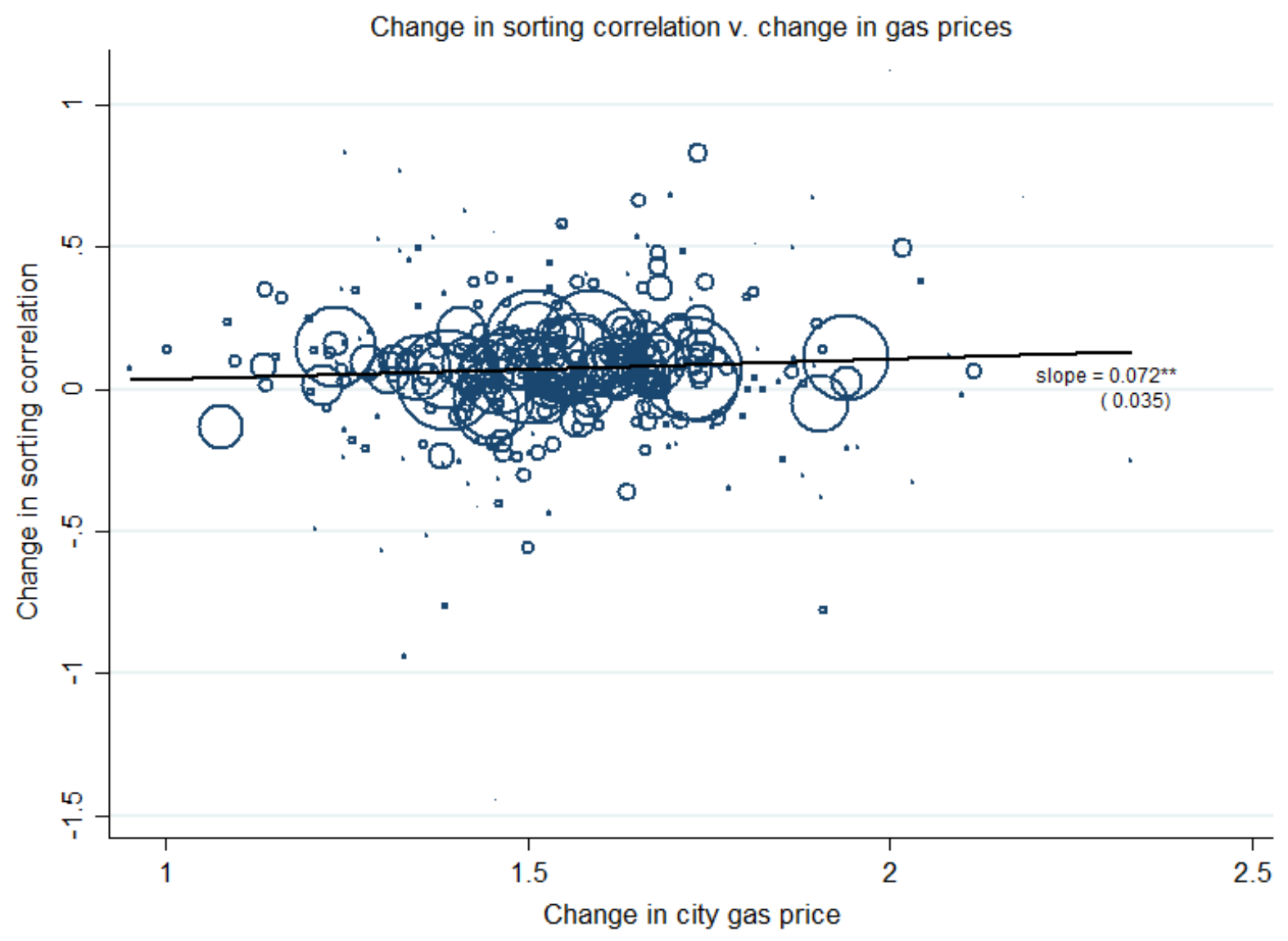

Notes: The figure shows the relationship between changes in city-specific gasoline prices and changes in city-specific MPG-VMT correlations between 2001 and 2009 NHTS. The slope and the standard error (in parentheses) of the predicted regression line are also reported. Positive slope indicates that MSAs that received larger changes in gasoline prices also experienced larger changes in the MPG-VMT correlations.

**Significant at the $5 \%$ level. 
Figure 6. MPG-VMT relationship for different tax regimes $($ Year $=2009)$

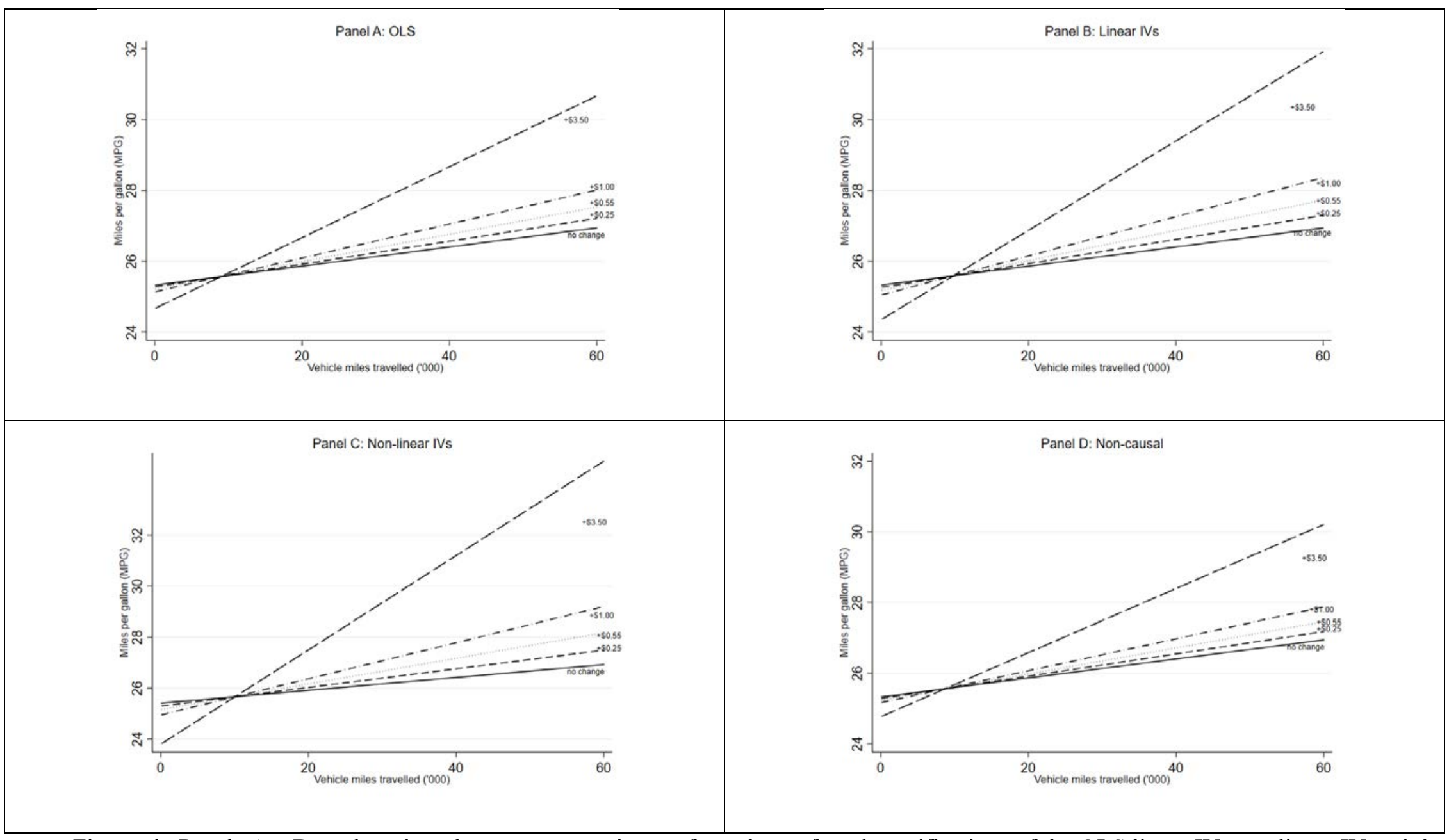

Notes: Figures in Panels A - D are based on the parameter estimates from the preferred specifications of the OLS linear IV, non-linear IV and the non-causal model, respectively. The predictions show the relationship between VMT and MPG when gasoline prices increase by $\$ 0.25$, $\$ 0.55$, $\$ 1$, and $\$ 3.50$. 
Figure 7: Within-Household Matching

A. Two-Car Households

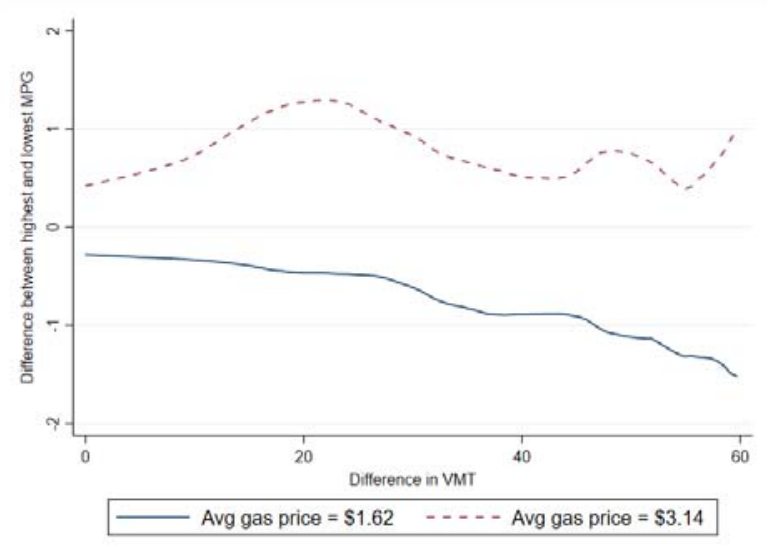

B. Three-Car Households

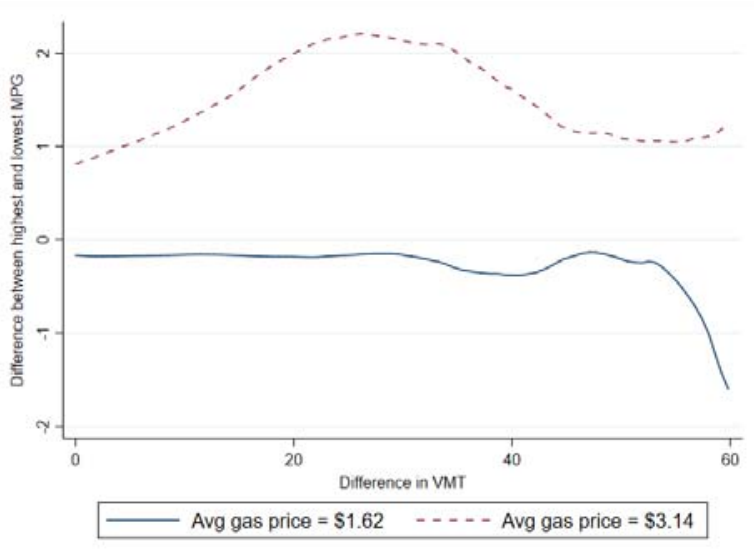

Notes: The figures show the difference in MPG of the car allocated to the highest VMT bundle in the household relative to the lowest, plotted against the respective differences in VMT. 
Table 1: Summary Statistics: 2001 \& 2009 National Household Travel Survey and Matched Gasoline Prices

\begin{tabular}{|c|c|c|c|c|}
\hline Variable & Full sample & 2001 NHTS & 2009 NHTS & Difference \\
\hline Gasoline price (2009 dollars) & $\begin{array}{c}2.834 \\
(0.855)\end{array}$ & $\begin{array}{c}1.635 \\
(0.214)\end{array}$ & $\begin{array}{c}3.138 \\
(0.670)\end{array}$ & $\begin{array}{c}1.503 * * * \\
(0.002)\end{array}$ \\
\hline Vehicle miles traveled (VMT) in '000 & $\begin{array}{l}10.280 \\
(8.277)\end{array}$ & $\begin{array}{l}11.138 \\
(8.640)\end{array}$ & $\begin{array}{c}9.980 \\
(8.124)\end{array}$ & $\begin{array}{c}-1.158 * * * \\
(0.033)\end{array}$ \\
\hline $\begin{array}{l}\text { Combined unadjusted fuel economy } \\
\text { (MPG) }\end{array}$ & $\begin{array}{l}25.551 \\
(6.094)\end{array}$ & $\begin{array}{l}25.400 \\
(5.280)\end{array}$ & $\begin{array}{l}25.599 \\
(6.332)\end{array}$ & $\begin{array}{l}0.199 * * * \\
(0.022)\end{array}$ \\
\hline Household size & $\begin{array}{c}2.666 \\
(1.288)\end{array}$ & $\begin{array}{c}2.816 \\
(1.353)\end{array}$ & $\begin{array}{c}2.614 \\
(1.260)\end{array}$ & $\begin{array}{c}-0.201 * * * \\
(0.005)\end{array}$ \\
\hline Number of workers in household & $\begin{array}{c}1.275 \\
(0.984)\end{array}$ & $\begin{array}{c}1.612 \\
(1.003)\end{array}$ & $\begin{array}{c}1.156 \\
(0.949)\end{array}$ & $\begin{array}{c}-0.456 * * * \\
(0.004)\end{array}$ \\
\hline Number of adults & $\begin{array}{c}2.085 \\
(0.711)\end{array}$ & $\begin{array}{c}2.081 \\
(0.721)\end{array}$ & $\begin{array}{c}2.087 \\
(0.708)\end{array}$ & $\begin{array}{l}0.006^{* *} \\
(0.003)\end{array}$ \\
\hline Fraction of children & $\begin{array}{c}0.139 \\
(0.216)\end{array}$ & $\begin{array}{c}0.176 \\
(0.233)\end{array}$ & $\begin{array}{c}0.126 \\
(0.208)\end{array}$ & $\begin{array}{c}-0.050 * * * \\
(0.001)\end{array}$ \\
\hline Fraction of women & $\begin{array}{c}0.518 \\
(0.230)\end{array}$ & $\begin{array}{c}0.508 \\
(0.237)\end{array}$ & $\begin{array}{c}0.522 \\
(0.228)\end{array}$ & $\begin{array}{c}0.014 * * * \\
(0.001)\end{array}$ \\
\hline Household income $<\$ 25,000$ & $\begin{array}{c}0.137 \\
(0.343)\end{array}$ & $\begin{array}{c}0.150 \\
(0.357)\end{array}$ & $\begin{array}{c}0.132 \\
(0.339)\end{array}$ & $\begin{array}{l}-0.018 * * * \\
(0.001)\end{array}$ \\
\hline $\begin{array}{l}\text { Household income }<\$ 50,000 \text { and } \geq \\
\$ 25,000\end{array}$ & $\begin{array}{c}0.271 \\
(0.444)\end{array}$ & $\begin{array}{c}0.327 \\
(0.469)\end{array}$ & $\begin{array}{c}0.251 \\
(0.434)\end{array}$ & $\begin{array}{l}-0.075 * * * \\
(0.002)\end{array}$ \\
\hline $\begin{array}{l}\text { Household income }<\$ 75,000 \text { and } \geq \\
\$ 50,000\end{array}$ & $\begin{array}{c}0.207 \\
(0.405)\end{array}$ & $\begin{array}{c}0.235 \\
(0.424)\end{array}$ & $\begin{array}{c}0.197 \\
(0.397)\end{array}$ & $\begin{array}{c}-0.038 * * * \\
(0.002)\end{array}$ \\
\hline Household income $\geq \$ 75,000$ & $\begin{array}{c}0.386 \\
(0.487)\end{array}$ & $\begin{array}{c}0.289 \\
(0.453)\end{array}$ & $\begin{array}{c}0.420 \\
(0.494)\end{array}$ & $\begin{array}{l}0.131 * * * \\
(0.002)\end{array}$ \\
\hline White, only & $\begin{array}{c}0.886 \\
(0.317)\end{array}$ & $\begin{array}{c}0.892 \\
(0.311)\end{array}$ & $\begin{array}{c}0.884 \\
(0.320)\end{array}$ & $\begin{array}{c}0.007 * * * \\
(0.001)\end{array}$ \\
\hline African-American, only & $\begin{array}{c}0.045 \\
(0.207)\end{array}$ & $\begin{array}{c}0.033 \\
(0.178)\end{array}$ & $\begin{array}{c}0.049 \\
(0.216)\end{array}$ & $\begin{array}{c}0.016 * * * \\
(0.001)\end{array}$ \\
\hline Asian, only & $\begin{array}{c}0.019 \\
(0.138)\end{array}$ & $\begin{array}{c}0.016 \\
(0.126)\end{array}$ & $\begin{array}{c}0.020 \\
(0.142)\end{array}$ & $\begin{array}{c}0.004 * * * \\
(0.000)\end{array}$ \\
\hline Number of households & 190,121 & 52,211 & 137,910 & \\
\hline
\end{tabular}

Notes: The main entries in columns 1,2 and 3 report the mean level of the variables with standard deviations in parentheses. Column 4 reports the differences and standard errors.

***Significant at the $1 \%$ level. **Significant at the $5 \%$ level. * Significant at the $10 \%$ level. 
Table 2. Difference-in-Differences Ordinary Least Squares Results

\begin{tabular}{|c|c|c|c|c|c|c|c|c|}
\hline & (1) & (2) & (3) & (4) & (5) & (6) & (7) & $(8)$ \\
\hline $\begin{array}{l}\text { Matching effect } \\
\text { (VMT x Price }{ }^{\text {gas }} \text { ) }\end{array}$ & $\begin{array}{c}0.02027 * * * \\
(\mathbf{0 . 0 0 3 5 )}\end{array}$ & $\begin{array}{c}0.02068 * * * \\
(0.0031)\end{array}$ & $\begin{array}{c}0.02006 * * * \\
(0.0032)\end{array}$ & $\begin{array}{c}0.02082 * * * \\
(0.0035)\end{array}$ & $\begin{array}{c}0.02169 * * * \\
(0.0031)\end{array}$ & $\begin{array}{c}0.02091 * * * \\
(0.0032)\end{array}$ & $\begin{array}{c}0.02119 * * * \\
(0.0034)\end{array}$ & $\begin{array}{l}\mathbf{0 . 0 2 0 9 3} * * * \\
(0.0032)\end{array}$ \\
\hline VMT & $\begin{array}{c}-0.04149 * * * \\
(0.0079)\end{array}$ & $\begin{array}{c}-0.04150^{* * *} \\
(0.0078)\end{array}$ & $\begin{array}{c}-0.03931 * * * \\
(0.0083)\end{array}$ & $\begin{array}{c}-0.03513 * * * \\
(0.0078)\end{array}$ & $\begin{array}{c}-0.03275^{* * *} \\
(0.0080)\end{array}$ & $\begin{array}{c}-0.03010^{* * *} \\
(0.0086)\end{array}$ & $\begin{array}{c}-0.03000^{* * *} \\
(0.0096)\end{array}$ & $\begin{array}{l}-0.03003 * * * \\
(0.0082)\end{array}$ \\
\hline Price gas & $\begin{array}{l}0.00176 \\
(0.0702)\end{array}$ & $\begin{array}{c}-0.10448 * * * \\
(0.0289)\end{array}$ & $\begin{array}{c}-0.17568 * * * \\
(0.0263)\end{array}$ & $\begin{array}{l}0.00166 \\
(0.0700)\end{array}$ & $\begin{array}{c}-0.10258 * * * \\
(0.0251)\end{array}$ & $\begin{array}{c}-0.18866^{* * *} \\
(0.0265)\end{array}$ & & $\begin{array}{l}-0.25026^{* *} \\
(0.1020)\end{array}$ \\
\hline MSA dummies & & $\mathrm{X}$ & $\mathrm{X}$ & & $\mathrm{X}$ & $\mathrm{X}$ & & $\mathrm{X}$ \\
\hline Year dummies & & & $\mathrm{X}$ & & & $\mathrm{X}$ & & $\mathrm{X}$ \\
\hline MSA-Month dummies & & & & & & & $\mathrm{X}$ & \\
\hline Demographic controls & & & & $\mathrm{X}$ & $\mathrm{X}$ & $\mathrm{X}$ & $\mathrm{X}$ & $\mathrm{X}$ \\
\hline $\begin{array}{l}\text { Price }^{\text {gas }} \times \text { Demographic } \\
\text { controls }\end{array}$ & & & & & & & & $\mathrm{X}$ \\
\hline $\mathrm{N}=$ & 326,372 & 326,372 & 326,372 & 304,637 & 304,637 & 304,637 & 304,637 & 304,637 \\
\hline $\mathrm{R}^{2}$ & 0.002 & 0.024 & 0.024 & 0.015 & 0.038 & 0.038 & 0.062 & 0.038 \\
\hline
\end{tabular}

Notes: The estimates are associated with the OLS model represented by Equation (6). The first column shows the results of the basic model with no controls. MSA dummies are added in column 2 and year dummies in column 3. Columns 4-6 repeat the first three columns, but add demographic controls. Column 6 represents the model in Equation (6) and is our preferred specification. Column 7 replaces the MSA and year dummies with MSA-month dummies, which also removes variation in gas prices. Column 8 includes interactions between demographic controls and gasoline prices. Demographic controls are number of household members, number of adults in the households, number of workers in the household, the fraction of children $($ age $<18)$ and women in the household and household income quartile. Standard errors clustered at the state level are in parentheses.

***Significant at the $1 \%$ level. **Significant at the $5 \%$ level. *Significant at the $10 \%$ level. 
Table 3. Difference-in-Differences with Linear Instruments $-2^{\text {nd }}$ Stage Results

(1)

\begin{tabular}{|c|c|c|c|c|}
\hline $\begin{array}{l}\text { Matching effect } \\
\text { (VMT x Price }^{\text {gas }} \text { ) }\end{array}$ & $\begin{array}{l}0.01795 * * \\
(0.0087)\end{array}$ & $\begin{array}{c}0.02612 * * * \\
(0.0073)\end{array}$ & $\begin{array}{c}0.02834 * * * \\
(0.0085)\end{array}$ & $\begin{array}{c}0.02510 * * * \\
(0.0091)\end{array}$ \\
\hline VMT & $\begin{array}{l}-0.16539 \\
(0.1419)\end{array}$ & $\begin{array}{l}-0.22640 \\
(0.1497)\end{array}$ & $\begin{array}{c}-0.36237 * * * \\
(0.1127)\end{array}$ & $\begin{array}{c}-0.35375 * * * \\
(0.1073)\end{array}$ \\
\hline Price ${ }^{\text {gas }}$ & $\begin{array}{l}-0.00542 \\
(0.1038)\end{array}$ & $\begin{array}{c}-0.18731 * * \\
(0.0767)\end{array}$ & $\begin{array}{c}-0.27781 * * * \\
(0.0911)\end{array}$ & \\
\hline MSA dummies & & $\mathrm{X}$ & $\mathrm{X}$ & \\
\hline Year dummies & & & $\mathrm{X}$ & \\
\hline MSA-Month dummies & & & & $\mathrm{X}$ \\
\hline Demographic controls & $\mathrm{X}$ & $\mathrm{X}$ & $\mathrm{X}$ & $\mathrm{X}$ \\
\hline $\begin{array}{l}\text { Price }^{\text {gas }} \times \text { Demographic } \\
\text { controls }\end{array}$ & Instr. & Instr. & Instr. & Instr. \\
\hline $\mathrm{N}=$ & 304,637 & 304,631 & 304,631 & 304,034 \\
\hline \multicolumn{5}{|c|}{ F-statistics of excluded instruments } \\
\hline VMT & 18.2 & 17.6 & 8.9 & 12.1 \\
\hline VMT $\times$ Price ${ }^{\text {gas }}$ & 393.9 & 220.6 & 196.6 & 190.9 \\
\hline
\end{tabular}

Notes: The estimates are associated with the coefficients estimates from the IV model represented by Equations (7) - (9), using demographics interacted with gas prices as excluded instruments. Column 1 omits MSA and year dummies, which are successively added in columns 2 and 3. Column 4 replaces the MSA and year dummies with MSA-month dummies, which also removes variation in gas prices. Demographic controls are number of household members, number of adults in the households, number of workers in the household, the fraction of children (age $<18)$ and women in the household and household income quartile. Standard errors clustered at the state level are reported in parentheses.

$* * *$ Significant at the $1 \%$ level. **Significant at the $5 \%$ level. * Significant at the $10 \%$ level. 
Table 4. Difference-in-Differences with Non-Linear Instruments $-2^{\text {nd }}$ Stage Results

\begin{tabular}{|c|c|c|c|c|c|}
\hline & (1) & (2) & (3) & (4) & (5) \\
\hline $\begin{array}{l}\text { Matching effect } \\
\text { (VMT x Price }{ }^{\text {gas }} \text { ) }\end{array}$ & $\begin{array}{l}\mathbf{0 . 0 1 3 0 3} \\
(\mathbf{0 . 0 1 2 4})\end{array}$ & $\begin{array}{c}0.04995 * * * \\
(0.0131)\end{array}$ & $\begin{array}{l}0.04567 * * * \\
(0.0126)\end{array}$ & $\begin{array}{c}0.04810 * * * \\
(0.0133)\end{array}$ & $\begin{array}{l}\mathbf{0 . 1 2 5 1 0} \\
(\mathbf{0 . 0 8 3 3 )}\end{array}$ \\
\hline$\widehat{V M T}_{i \bar{c} m t}$ & $\begin{array}{c}0.19345^{* *} \\
(0.0898)\end{array}$ & $\begin{array}{l}-0.05216 \\
(0.0658)\end{array}$ & $\begin{array}{l}-0.03613 \\
(0.0657)\end{array}$ & $\begin{array}{l}-0.05365 \\
(0.0666)\end{array}$ & $\begin{array}{l}-0.23407 \\
(0.1822)\end{array}$ \\
\hline Price gas & $\begin{array}{l}0.12687 \\
(0.1590)\end{array}$ & $\begin{array}{c}-0.40959 * * * \\
(0.1331)\end{array}$ & $\begin{array}{c}-0.46045^{* * *} \\
(0.1318)\end{array}$ & & $\begin{array}{c}-1.10281^{* *} \\
(0.5601)\end{array}$ \\
\hline MSA dummies & & $\mathrm{X}$ & $\mathrm{X}$ & & $\mathrm{X}$ \\
\hline Year dummies & & & $\mathrm{X}$ & & $\mathrm{X}$ \\
\hline MSA-Month dummies & & & & $\mathrm{X}$ & \\
\hline Demographic controls & $\mathrm{X}$ & $\mathrm{X}$ & $\mathrm{X}$ & $X$ & $\mathrm{X}$ \\
\hline $\begin{array}{l}\text { Price }{ }^{\text {gas }} \times \text { Demo- } \\
\text { graphic controls }\end{array}$ & & & & & $\mathrm{X}$ \\
\hline $\mathrm{N}=$ & 270,146 & 270,138 & 270,138 & 269,419 & 270,138 \\
\hline \multicolumn{6}{|c|}{ F-statistics of excluded instruments } \\
\hline$\widehat{V M T}_{i \bar{c} m t}$ & 20.9 & 23.8 & 22.7 & 18.3 & 23.6 \\
\hline$\widehat{V M T}_{i \bar{c} m t} \times$ Price $^{\mathrm{gas}}$ & 138.3 & 118.7 & 135.1 & 163.2 & 23.9 \\
\hline
\end{tabular}

Notes: The estimates reported are coefficients estimates for the second stage of the model represented by Equation (13). $\widehat{V M T}_{i \bar{c} m t}$ as predicted from the structural model of Bento et al. (2009) serves as the instrument for VMT. Column 1 omits MSA and year dummies, which are successively added in columns 2 and 3. Column 4 replaces the MSA and year dummies with MSA-month dummies, which also removes variation in gas prices. Column 5 includes demographics interacted with price in the structural equation. Demographic controls are number of household members, number of adults in the households, number of workers in the household, the fraction of children $($ age $<18)$ and women in the household and household income quartile. Standard errors clustered at the state level are reported in parentheses.

***Significant at the $1 \%$ level. ** Significant at the 5\% level. * Significant at the $10 \%$ level. 
Table 5. Non-causal estimation of the matching effect

\begin{tabular}{|c|c|c|c|c|}
\hline & (1) & (2) & (3) & (4) \\
\hline $\begin{array}{l}\text { Matching effect } \\
\text { ( } \overline{\text { VMT }} \times \text { Price } \\
\text { gas }\end{array}$ & $\begin{array}{l}0.01690^{*} \\
(0.0097)\end{array}$ & $\begin{array}{c}0.02117 * * * \\
(0.0075)\end{array}$ & $\begin{array}{c}0.01829 * * \\
(0.0081)\end{array}$ & $\begin{array}{c}0.01986 * * \\
(0.0085)\end{array}$ \\
\hline VMT & \multicolumn{4}{|c|}{ Not identified } \\
\hline Price gas $^{\text {gas }}$ & $\begin{array}{l}0.03864 \\
(0.1403)\end{array}$ & $\begin{array}{l}-0.10021 \\
(0.0754)\end{array}$ & $\begin{array}{c}-0.16299 * * \\
(0.0791)\end{array}$ & N/A \\
\hline MSA FE & & $\mathrm{X}$ & $\mathrm{X}$ & \\
\hline Year FE & & & $\mathrm{X}$ & \\
\hline MSA-Month FE & & & & $\mathrm{X}$ \\
\hline Demographic controls & $\mathrm{X}$ & $\mathrm{X}$ & $\mathrm{X}$ & $\mathrm{X}$ \\
\hline $\mathrm{N}=$ & 304,637 & 304,637 & 304,637 & 304,637 \\
\hline $\mathrm{R}^{2}$ & 0.013 & 0.036 & 0.036 & 0.060 \\
\hline
\end{tabular}

Notes: The estimates are associated with coefficients estimates of the model represented by Equation (17). Predicted VMT is a function of average gasoline prices, demographic characteristics, interactions between these characteristics and average gasoline prices, year dummies and MSA dummies. Corrected standard errors are reported in parentheses.

$* * *$ Significant at the $1 \%$ level. **Significant at the $5 \%$ level. *Significant at the $10 \%$ level. 
Table 6. Difference-in-Differences using Gallons-per-Mile

\begin{tabular}{|c|c|c|c|c|}
\hline & (1) & (2) & (3) & (4) \\
\hline & OLS & IV-lin & IV-nonlin & Non-causal \\
\hline $\begin{array}{l}\text { Matching effect } \\
\text { (VMT x Pricegas) }\end{array}$ & $\begin{array}{c}-0.02626 * * * * \\
(0.0048)\end{array}$ & $\begin{array}{c}-0.03011^{* *} \\
(0.0150)\end{array}$ & $\begin{array}{c}-0.07034 * * * \\
(0.0213)\end{array}$ & $\begin{array}{l}-0.01718 \\
(0.0129)\end{array}$ \\
\hline VMT & $\begin{array}{c}0.04283^{* * * *} \\
(0.0122)\end{array}$ & $\begin{array}{c}0.50233 * * * \\
(0.1584)\end{array}$ & $\begin{array}{l}0.07288 \\
(0.1034)\end{array}$ & \\
\hline Price gas & $\begin{array}{c}0.20975^{* * * *} \\
(0.0423)\end{array}$ & $\begin{array}{l}0.26835^{*} \\
(0.1617)\end{array}$ & $\begin{array}{c}0.68844 * * * \\
(0.2294)\end{array}$ & $\begin{array}{l}0.11845 \\
(0.1304)\end{array}$ \\
\hline MSA FE & $\mathrm{X}$ & $\mathrm{X}$ & $\mathrm{X}$ & $X$ \\
\hline Year FE & $\mathrm{X}$ & $\mathrm{X}$ & $\mathrm{X}$ & $\mathrm{X}$ \\
\hline Demographic Controls & $\mathrm{X}$ & $\mathrm{X}$ & $\mathrm{X}$ & $\mathrm{X}$ \\
\hline $\mathrm{N}=$ & 304,637 & 304,631 & 270,138 & 304,637 \\
\hline Instruments: & -- & $\begin{array}{c}\text { Price }^{\text {gas }} \times \text { De- } \\
\text { mographic } \\
\text { controls }\end{array}$ & $\begin{array}{l}\widehat{V M T}_{i \bar{\jmath}} \\
\widehat{V M T}_{i \bar{\jmath}} \times \\
\text { Price }^{\text {gas }}\end{array}$ & -- \\
\hline Compare to: & $\begin{array}{l}\text { Table } 2 \\
\text { Col. } 6\end{array}$ & $\begin{array}{l}\text { Table } 3 \\
\text { Col. } 3\end{array}$ & $\begin{array}{l}\text { Table } 4 \\
\text { Col. } 3\end{array}$ & $\begin{array}{l}\text { Table } 5 \\
\text { Col. } 3\end{array}$ \\
\hline $\begin{array}{l}\text { Equivalent value of matching effect } \\
\text { for MPG at mean }\end{array}$ & $0.0155^{* * *}$ & $0.0179 * *$ & $0.0417^{* * *}$ & 0.0102 \\
\hline
\end{tabular}

Notes: The dependent variable in these regressions is $1000 \times$ GPM. The columns correspond to selected models from Tables 2, 3, 4, and 5 respectively. In Column 3, $\widehat{V T T}_{i \bar{c} m t}$ is estimated using Bento et al. (2009) structural model. Standard errors clustered at the state level are reported in parentheses. The unit of observation is the vehicle.

*** Significant at the $1 \%$ level. **Significant at the $5 \%$ level. *Significant at the $10 \%$ level. 
Table 7. Between-Household Analysis

\begin{tabular}{|c|c|c|c|c|}
\hline & (1) & (2) & (3) & (4) \\
\hline & OLS & IV-lin & IV-nonlin & Non-causal \\
\hline \multicolumn{5}{|l|}{ A. Avg. MPG } \\
\hline $\begin{array}{l}\text { Matching effect } \\
(\mathrm{N}=160,539)\end{array}$ & $\begin{array}{c}0.00753 * * * \\
(0.0021)\end{array}$ & $\begin{array}{c}0.02474 * * * \\
(0.0056)\end{array}$ & $\begin{array}{c}0.03134 * * * \\
(0.0084)\end{array}$ & $\begin{array}{c}0.02093 * * * \\
(0.0052)\end{array}$ \\
\hline \multicolumn{5}{|l|}{ B. Top Car } \\
\hline $\begin{array}{l}\text { Matching effect } \\
(\mathrm{N}=159,815)\end{array}$ & $\begin{array}{l}0.01165 * * * \\
\quad(0.0022)\end{array}$ & $\begin{array}{c}0.03642 * * * \\
\quad(0.0076)\end{array}$ & $\begin{array}{c}0.03971 * * * \\
\quad(0.0107)\end{array}$ & $\begin{array}{c}0.02381 * * * \\
(0.0053)\end{array}$ \\
\hline \multicolumn{5}{|l|}{ C. One-Car Households } \\
\hline $\begin{array}{l}\text { Matching effect } \\
(\mathrm{N}=76,321)\end{array}$ & $\begin{array}{c}0.01073 * * * \\
\quad(0.0030)\end{array}$ & $\begin{array}{l}0.04535 * * * \\
\quad(0.0117)\end{array}$ & $\begin{array}{l}0.01378 \\
(0.0144)\end{array}$ & $\begin{array}{c}0.02219 * * * \\
(0.0076)\end{array}$ \\
\hline MSA FE & $\mathrm{X}$ & $\mathrm{X}$ & $\mathrm{X}$ & $\mathrm{X}$ \\
\hline Year FE & $\mathrm{X}$ & $\mathrm{X}$ & $\mathrm{X}$ & $\mathrm{X}$ \\
\hline Demographic Controls & $\mathrm{X}$ & $\mathrm{X}$ & $\mathrm{X}$ & $\mathrm{X}$ \\
\hline
\end{tabular}

Notes: Each household is one observation. Panel A uses the households average MPG. Panel B uses the MPG of the highest-VMT car. Panel C uses only one-car households. All specifications control for year dummies and MSA dummies and household characteristics.

***Significant at the $1 \%$ level. **Significant at the $5 \%$ level. * Significant at the $10 \%$ level. 
Table 8. Matching Effect of Gasoline Taxes

\begin{tabular}{|c|c|c|c|c|c|}
\hline & (1) & (2) & (3) & (4) & (5) \\
\hline \multicolumn{6}{|l|}{ Panel A. OLS. } \\
\hline $\begin{array}{l}\text { Matching effect } \\
\text { (VMT x Tax) }\end{array}$ & $\begin{array}{l}0.06404 * * * \\
\quad(0.0116)\end{array}$ & $\begin{array}{l}0.06409 * * * \\
\quad(0.0119)\end{array}$ & $\begin{array}{c}0.06212 * \\
(0.0371)\end{array}$ & $\begin{array}{l}0.06154 * \\
(0.0371)\end{array}$ & $\begin{array}{l}0.06212 * \\
(0.0375)\end{array}$ \\
\hline $\begin{array}{l}\text { Matching effect } \\
\text { (VMT x Net-of-Tax P) }\end{array}$ & $\begin{array}{l}0.01844 * * * \\
\quad(0.0016)\end{array}$ & $\begin{array}{l}0.01905 * * * \\
\quad(0.0017)\end{array}$ & $\begin{array}{l}0.01937 * * * \\
\quad(0.0046)\end{array}$ & $\begin{array}{l}0.01857 * * * \\
\quad(0.0048)\end{array}$ & $\begin{array}{c}0.01882 * * * \\
(0.0050)\end{array}$ \\
\hline \multicolumn{6}{|l|}{$\begin{array}{l}\text { Panel B. IV using gas } \\
\text { tax as instrument }\end{array}$} \\
\hline $\begin{array}{l}\text { Matching effect } \\
\text { (VMT x Price }^{\text {gas }} \text { ) }\end{array}$ & $\begin{array}{c}0.03099 * * \\
(0.0154)\end{array}$ & $\begin{array}{c}0.03036^{* * *} \\
(0.0150) \\
\end{array}$ & $\begin{array}{c}0.03624 * * * \\
(0.0126)\end{array}$ & $\begin{array}{c}0.03578 * * * \\
(0.0126)\end{array}$ & $\begin{array}{c}0.03662 * * * \\
(0.0133)\end{array}$ \\
\hline MSA dummies & & & $\mathrm{X}$ & $\mathrm{X}$ & \\
\hline Year dummies & & & & $\mathrm{X}$ & \\
\hline MSA-Month dummies & & & & & $\mathrm{X}$ \\
\hline Demographic controls & & $\mathrm{X}$ & $\mathrm{X}$ & $\mathrm{X}$ & $\mathrm{X}$ \\
\hline $\mathrm{N}=$ & 322,866 & 301,311 & 301,311 & 301,311 & 301,311 \\
\hline
\end{tabular}

This table shows the matching effect from gasoline taxes. Panel A separately estimates the matching effect from taxes from the net-of-tax portion of gas prices. Panel B estimates the effect of gasoline prices when gasoline taxes are used as an instrument. 


\section{Appendix A. Derivation of Equation (5).}

We begin by taking the derivative of the expression for WTP in Equation (4) with respect to the car type $c$. Making use of Leibniz's rule when differentiating $V M T^{*}$ in the limits of integration, we obtain:

$$
\begin{aligned}
& \frac{\partial W T P\left(c, i, p^{G}\right)}{\partial c}=\frac{\partial f(c, i)}{\partial c}+\int_{0}^{V M T^{*}\left(c, i, p^{G}\right)} \frac{\partial \pi(c, i, V M T)}{\partial c} d V M T \\
& +\frac{\partial V M T^{*}\left(c, i, p^{G}\right)}{\partial c}\left[\pi\left(c, i, V M T^{*}\right)-G P M(c) p^{G}\right] \\
& -V M T^{*}\left(c, i, p^{G}\right) \frac{\partial G P M}{\partial c} p^{G} \text {. }
\end{aligned}
$$

This expression shows how the WTP for a car changes with the car type, as a function of the individual type and gasoline prices. Next, we take the cross partial derivative with respect to the individuals' utilization type.

$$
\begin{aligned}
& \frac{\partial^{2} f(c, i)}{\partial c \partial i}+\int_{0}^{V M T^{*}\left(c, i, p^{G}\right)} \frac{\partial^{2} \pi\left(c, i, V M T^{*}\right)}{\partial c \partial i} d V M T \\
\frac{\partial^{2} W T P\left(c, i, p^{G}\right)}{\partial c \partial i}=\quad & +\frac{\partial V M T^{*}\left(c, i, p^{G}\right)}{\partial i}\left[\frac{\partial \pi\left(c, i, V M T^{*}\right)}{\partial c}-\frac{d G P M(c)}{d c} p^{G}\right] \\
& +\frac{\partial V M T^{*}\left(c, i, p^{G}\right)}{\partial c} \frac{\partial \pi\left(c, i, V M T^{*}\right)}{\partial i} \\
+ & \frac{\partial^{2} V M T^{*}\left(c, i, p^{G}\right)}{\partial c \partial i}\left[\pi\left(c, i, V M T^{*}\right)-G P M(c) p^{G}\right] .
\end{aligned}
$$

Now taking the third derivative with respect to $p^{G}$ :

$$
\begin{gathered}
\frac{\partial V M T^{*}\left(c, i, p^{G}\right)}{\partial p^{G}} \frac{\partial^{2} \pi\left(c, i, V M T^{*}\right)}{\partial c \partial i}-\frac{\partial V M T^{*}\left(c, i, p^{G}\right)}{\partial i} \frac{d G P M(c)}{d c} \\
\frac{\partial^{3} W T P\left(c, i, p^{G}\right)}{\partial c \partial i \partial p^{G}}=+\frac{\partial^{2} V M T^{*}\left(c, i, p^{G}\right)}{\partial i \partial p^{G}}\left[\frac{\partial \pi\left(c, i, V M T^{*}\right)}{\partial c}-\frac{d G P M(c)}{d c} p^{G}\right] \\
+\frac{\partial^{2} V M T^{*}\left(c, i, p^{G}\right)}{\partial c \partial p^{G}} \frac{\partial \pi\left(c, i, V M T^{*}\right)}{\partial i}-\frac{\partial^{2} V M T^{*}\left(c, i, p^{G}\right)}{\partial c \partial i} G P M \\
+\frac{\partial^{3} V M T^{*}\left(c, i, p^{G}\right)}{\partial c \partial i \partial p^{G}}\left[\pi\left(c, i, V M T^{*}\right)-G P M(c) p^{G}\right] .
\end{gathered}
$$

But by the first-order condition for optimal VMT conditional on $c, \pi\left(c, i, V M T^{*}\right)=G P M(c) p^{G}$; that is, the marginal WTP for VMT equals the marginal cost. Thus, the last term in (A3) drops out 
and we are left, after re-arranging some terms, with:

$$
\begin{gathered}
-\frac{\partial V M T^{*}\left(c, i, p^{G}\right)}{\partial i} \frac{d G P M(c)}{d c} \\
\frac{\partial^{3} W T P\left(c, i, p^{G}\right)}{\partial c \partial i \partial p^{G}}=\quad \frac{\partial^{2} V M T^{*}\left(c, i, p^{G}\right)}{\partial c \partial p^{G}} \frac{\partial\left(c, i, V M T^{*}\right)}{\partial i} \\
\frac{\partial V M T^{*}\left(c, i, p^{G}\right)}{\partial p^{G}} \frac{\partial^{2} \pi\left(c, i, V M T^{*}\right)}{\partial c \partial i}-\frac{\partial^{2} V M T^{*}\left(c, i, p^{G}\right)}{\partial c \partial i} G P M \\
+\frac{\partial^{2} V M T^{*}\left(c, i, p^{G}\right)}{\partial i \partial p^{G}}\left[\frac{\partial \pi\left(c, i, V M T^{*}\right)}{\partial c}-\frac{d G P M(c)}{d c} p^{G}\right] .
\end{gathered}
$$




\section{Appendix B. Proof of the non-causal model}

Consider the following two simultaneous equations:

$$
\begin{aligned}
& y_{1}=\alpha+\beta x_{1}+\delta x_{2}+\theta\left[x_{1} \cdot x_{2}\right]+\varepsilon \\
& y_{2}=a+b x_{1}+c x_{2}+d\left[x_{1} \cdot x_{2}\right]+\mu
\end{aligned}
$$

where $\mathrm{E}\left(x_{1} \varepsilon\right)=\mathrm{E}\left(x_{2} \varepsilon\right)=\mathrm{E}\left(x_{1} \mu\right)=\mathrm{E}\left(x_{2} \mu\right)=0 . \quad$ Let $\mathbf{X}_{1}=\left[1 x_{1}\right], \quad \mathbf{X}_{2}=\left[x_{2} x_{1} \cdot x_{2}\right], \quad \mathbf{X}=$ $\left[\mathbf{X}_{\mathbf{1}} \mathbf{X}_{\mathbf{2}}\right], \mathbf{A}_{\mathbf{1}}=[\alpha \beta]^{\prime}$ and $\mathbf{A}_{\mathbf{2}}=[\delta \theta]^{\prime}$. Given the orthogonality conditions, (B1) and (B2) can be estimated by OLS. By the Frisch-Waugh-Lovell theorem:

$$
\widehat{\mathbf{A}_{2}}=\left(\mathbf{X}_{2}^{\prime} \mathbf{M}_{1} \mathbf{X}_{2}\right)^{-1} \mathbf{X}_{2}^{\prime} \mathbf{M}_{1} y_{1}
$$

where $\mathbf{M}_{\mathbf{i}}=\mathbf{I}-\mathbf{P}_{\mathbf{X}_{\mathbf{i}}}=\mathbf{I}-\mathbf{X}_{\mathbf{i}}\left(\mathbf{X}_{\mathbf{i}}^{\prime} \mathbf{X}_{\mathbf{i}}\right)^{-1} \mathbf{X}_{\mathbf{i}}^{\prime} \cdot \mathbf{P}_{\mathbf{X}_{\mathbf{i}}}$ is the projection matrix onto the space spanned by the columns of $\mathbf{X}_{\mathbf{i}}$ and $\mathbf{X}_{\mathbf{i}}^{\prime} \mathbf{M}_{\mathbf{i}}=\mathbf{0} \cdot \frac{\partial \mathrm{E}\left(y_{1} \mid \mathbf{X}\right)}{\partial x_{2}}=\hat{\delta}+\hat{\theta} x_{1}=\mathbf{X}_{\mathbf{1}} \widehat{\mathbf{A}_{\mathbf{2}}}$. Call this $\hat{T}$; this is the estimated treatment effect of $x_{2}$. To estimate how $\partial x_{2}$ is correlated with $\widehat{y_{2}}$, estimate the following regression:

$$
\widehat{T}=\pi_{0}+\pi_{1} \widehat{y_{2}}+\omega
$$

where $\widehat{y_{2}}=\hat{a}+\hat{b} x_{1}+\hat{c} \overline{x_{2}}+\hat{d}\left[x_{1} \cdot \overline{x_{2}}\right]$, the structural parameters are estimated by OLS and $\overline{x_{2}}=$ $\sum_{i=1}^{N} \frac{x_{2_{i}}}{N}$. Let $\mathbf{X}_{3}=\left[1 \widehat{y_{2}}\right]$ and $\boldsymbol{\Pi}=\left[\pi_{0} \pi_{1}\right]^{\prime}$.

$$
\begin{gathered}
\widehat{\boldsymbol{\Pi}}=\left(\mathbf{X}_{3}^{\prime} \mathbf{X}_{3}\right)^{-1} \mathbf{X}_{3}^{\prime} \widehat{T} \\
\widehat{\boldsymbol{\Pi}}=\left(\mathbf{X}_{3}^{\prime} \mathbf{X}_{3}\right)^{-1} \mathbf{X}_{3}^{\prime} \mathbf{X}_{1} \widehat{\mathbf{A}_{2}} \\
\widehat{\boldsymbol{\Pi}}=\left(\mathbf{X}_{3}^{\prime} \mathbf{X}_{3}\right)^{-1} \mathbf{X}_{3}^{\prime} \mathbf{X}_{1}\left(\mathbf{X}_{2}^{\prime} \mathbf{M}_{1} \mathbf{X}_{2}\right)^{-1} \mathbf{X}_{2}^{\prime} \mathbf{M}_{1} y_{1}
\end{gathered}
$$

Now consider the following model:

$$
y_{1}=\alpha+\beta x_{1}+\pi_{0} x_{2}+\pi_{1}\left[\widehat{y_{2}} \cdot x_{2}\right]+\xi
$$

where $\mathbf{X}_{\mathbf{4}}=\left[x_{2} \widehat{y_{2}} \cdot x_{2}\right]$. By the Frisch-Waugh-Lovell theorem:

$$
\widehat{\mathbf{B}}=\left(\mathbf{X}_{4}^{\prime} \mathbf{M}_{1} \mathbf{X}_{4}\right)^{-1} \mathbf{X}_{4}^{\prime} \mathbf{M}_{1} y_{1}
$$


Note that the projection of $y_{1}$ onto the space defined by $\mathbf{X}_{\mathbf{1}}$ will be the same for (B1) and (B6). This implies that $\mathbf{M}_{\mathbf{2}}=\mathbf{M}_{\mathbf{4}}$ : the partial effects of $\mathbf{X}_{\mathbf{1}}$ in (B1) can be obtained when the residuals from a regression of $y_{1}$ on $\mathbf{X}_{2}$ are regressed on the set of residuals obtained when each column of $\mathbf{X}_{\mathbf{1}}$ is regressed on $\mathbf{X}_{2}$. The partial effects of $\mathbf{X}_{\mathbf{1}}$ in (B6) can be obtained when the residuals from a regression $y_{1}$ on $\mathbf{X}_{4}$ are regressed on the set of residuals obtained when each column of $\mathbf{X}_{\mathbf{1}}$ is regressed on $\mathbf{X}_{\mathbf{4}}$. Hence, in both cases the residual-maker is the same and $\mathbf{M}_{\mathbf{2}}=\mathbf{M}_{\mathbf{4}}$. Given this results, the fact that $\mathbf{X}_{\mathbf{i}}^{\prime} \mathbf{M}_{\mathbf{i}}=\mathbf{0}$ and using (B5) and (B7) we have,

$$
\begin{gathered}
\left(\mathbf{X}_{3}^{\prime} \mathbf{X}_{3}\right)^{-1} \mathbf{X}_{3}^{\prime} \mathbf{X}_{\mathbf{1}}\left(\mathbf{X}_{2}^{\prime} \mathbf{M}_{1} \mathbf{X}_{2}\right)^{-1} \mathbf{X}_{2}^{\prime} \mathbf{M}_{2} \mathbf{M}_{1} y_{1}=\left(\mathbf{X}_{4}^{\prime} \mathbf{M}_{1} \mathbf{X}_{4}\right)^{-1} \mathbf{X}_{4}^{\prime} \mathbf{M}_{4} \mathbf{M}_{1} y_{1} \\
\left(\mathbf{X}_{3}^{\prime} \mathbf{X}_{3}\right)^{-1} \mathbf{X}_{3}^{\prime} \mathbf{X}_{\mathbf{1}}\left(\mathbf{X}_{2}^{\prime} \mathbf{M}_{1} \mathbf{X}_{2}\right)^{-1} \mathbf{X}_{2}^{\prime} \mathbf{M}_{2} \mathbf{M}_{1} y_{1}=\left(\mathbf{X}_{4}^{\prime} \mathbf{M}_{1} \mathbf{X}_{4}\right)^{-1} \mathbf{X}_{4}^{\prime} \mathbf{M}_{2} \mathbf{M}_{1} y_{1} \\
\left(\mathbf{X}_{3}^{\prime} \mathbf{X}_{3}\right)^{-1} \mathbf{X}_{3}^{\prime} \mathbf{X}_{\mathbf{1}}\left(\mathbf{X}_{2}^{\prime} \mathbf{M}_{1} \mathbf{X}_{2}\right)^{-1} \mathbf{X}_{2}^{\prime} \mathbf{M}_{1} y_{1}=\left(\mathbf{X}_{4}^{\prime} \mathbf{M}_{1} \mathbf{X}_{4}\right)^{-1} \mathbf{X}_{4}^{\prime} \mathbf{M}_{1} y_{1} \\
\widehat{\Pi}=\widehat{\mathbf{B}}
\end{gathered}
$$

